\begin{tabular}{lllr} 
Submission: 02/04/2020; & $1^{\text {st }}$ round notif.: 08/05/2020; & New version: 08/06/2020; \\
Camera ready: 20/07/2020; & Edition review: 01/10/2020; & Available online: $12 / 10 / 2020 ;$ & Published: $11 / 10 / 2020$ \\
\hline
\end{tabular}

\title{
Um Modelo para Inter-relação entre Funções Executivas e Elementos de Jogos Digitais
}

\author{
Title: A Model for the Interrelationship between Executive Functions and Elements of Digital \\ Games
}

Katiane Kazuza Gneipel Krause Universidade do Estado de

Santa Catarina

kati.kazuza@gmail.com

\author{
Marcelo da Silva Hounsell \\ Universidade do Estado de \\ Santa Catarina \\ marcelo.hounsell@udesc.br
}

\author{
Isabela Gasparini \\ Universidade do Estado de \\ Santa Catarina \\ isabela.gasparini@udesc.br
}

\begin{abstract}
Resumo
As funções executivas (FE) são um conjunto de habilidades cognitivas de alto nível, formadas pelo controle inibitório, memória de trabalho e flexibilidade cognitiva. Elas permitem que a pessoa desenvolva autodisciplina, controle e gerencie a atenção e o comportamento durante ações dirigidas a objetivos, por exemplo, durante a resolução de problemas cognitivos e dos desafios presentes em jogos digitais (JD). Estes são delineados pelas mecânicas e estratégias de modelagem da dificuldade (level design). A partir dos resultados de uma revisão sistemática da literatura e um workshop, ambos sobre FE e JD, foi possível estabelecer uma relação entre mecânicas de JD e FE e estratégias de level design e FE. Este artigo não somente identifica todos os tipos de mecânica e level design intimamente relacionados com as FE, mas também apresenta uma inter-relação com os três componentes de FE, denominado de Modelo de Interação Cognitiva Jogo-Jogador (IcJJ). O IcJJ envolve a interação do jogador com o JD, mostrando atributos cognitivos de alto nível, através da relação entre 12 mecânicas de JD, 8 estratégias de level design e três componentes de FE. O modelo IcJJ pode servir de suporte para exploração e identificação do potencial cognitivo dos JD, especialmente daqueles aplicados no contexto educacional ou como referencial para o desenvolvimento de JD sérios, focados em FE.
\end{abstract}

Palavras-chave: cognição; funções executivas; jogos digitais; mecânicas; interação jogo-jogador; game design; IcJJ.

\begin{abstract}
Executive functions $(E F)$ are high-level cognitive skills, composed of inhibitory control, working memory and cognitive flexibility. They enable the person to develop self-discipline, control and manage attention and behavior during objectives drive actions, such as when solving problems and challenges present in digital games (DG). The problems and challenges are outlined by game elements such as mechanics and actions (level design). Based on the results of a systematic review and a workshop both on EF and DG, from literature, it was possible to draw a relationship between DG mechanics and EF. At the same time, it was possible to draw a relationship between DG level design and EF. This paper not only identifies all sort of strategic of the mechanics and level design closely related to EF but also present an interrelationship of all three components, called the Game-Player Interaction Cognitive Model (ICJJ). The IcJJ involves the player's interaction with the DG, showing high-level cognitive attributes, through the relationship among 12 DG mechanics, 8 level design strategies and three EF components. IcJJ model can serves as a support for the exploration and analysis of the DG's cognitive potential, especially those applied in the educational context or as a reference for the development of serious DG, focused on EF. Keywords: cognition; executive functions; digital games; mechanics; player-game interaction; game design; IcJJ.
\end{abstract}

Cite as: Krause, K. K. G., Hounsell, M. S., \& Gasparini, I. (2020). A Model for the Interrelationship between Executive Functions and Elements of Digital Games (Um modelo para inter-relação entre funções executivas e elementos de jogos digitais). Brazilian Journal of Computers in Education (Revista Brasileira de Informática na Educação - RBIE), 28, 596-625. DOI: 10.5753/RBIE.2020.28.0.596 


\section{Introdução}

A atividade de jogar um jogo digital (JD) requer manuseio de dispositivos através dos quais o jogador controla as ações e interage com o ambiente do jogo, no intuito de solucionar desafios, enfrentar inimigos, adquirir habilidades ou decifrar enigmas, encorajado pelos mecanismos que transformam essas ações em entretenimento, juntamente com os componentes narrativos e estéticos (Novak, 2010).

Em conjunto, este tipo de interação requer do jogador capacidades de planejamento, autorregulação e coordenação de recursos motores e cognitivos para resolução dos problemas. Isso significa que o jogador necessita dirigir e manter sua atenção para uma meta específica (objetivo do jogo), organizando e adaptando suas ações conforme as respostas que o jogo oferta. Por exemplo, ter de interromper a ação em curso e rapidamente mudar de estratégia, manipulando elementos para resolver enigmas e prosseguir no jogo (Palaus et al, 2017).

A necessidade desta "ginástica cerebral" caracteriza a atividade de jogar numa tarefa cognitiva complexa, assim como efetuar cálculos mentais, aprender uma segunda língua, interpretar um texto ou executar atividades corriqueiras e que requerem a interação intencional da pessoa com o ambiente, de maneira adaptativa, automonitorada e direcionada a um objetivo (Katz, 2008). Os JD requerem funções cognitivas de alto nível como as Funções Executivas (FE), um conjunto de capacidades de autogerenciamento da atenção e do comportamento (controle inibitório, memória de trabalho, flexibilidade cognitiva), que possibilitam a pessoa ser menos suscetível a ações impulsivas e reativas enquanto executa uma tarefa, mantendo a atenção direcionada ao objetivo (Diamond, 2013).

Esta idiossincrasia nos JD fomenta o estudo de sua viabilidade para aplicação em campos externos ao entretenimento, como saúde e educação. Por consequência, investiga-se também a natureza cognitiva dos constructos de JD. Há evidências, por exemplo, de que a prática em jogos de ação melhora a orientação espacial e funções executivas (Powers et al, 2013), e que os jogos de ação são mais eficazes no aprimoramento da atenção seletiva em

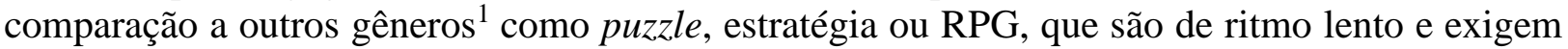
habilidades de planejamento e controle cognitivo (Palaus et al, 2017).

Boot et al (2008), entretanto, no estudo sobre a influência dos JD de ação na cognição, enfatizam que há diversos níveis de dificuldade num mesmo gênero, sugerindo a desconstrução de jogos complexos em pequenos jogos quando se deseja avaliar habilidades específicas aprendidas em ambiente de jogo e seu efeito de transferência ${ }^{2}$. Um exemplo desta "desconstrução" é a estratégia de Mossmann et al (2017) em compor o JD sério "As incríveis aventuras de Apollo e Rosetta no espaço" em vários minigames, cada qual direcionado para desenvolver uma das FE (controle inibitório, memória de trabalho, flexibilidade cognitiva).

Clark et al (2016) vão além desta visão voltada para o gênero e defendem que o design do jogo como um todo - estética, organização da informação, teoria de aprendizagem subjacente - afeta a interação jogo-jogador e por consequência, influencia os resultados no aprendizado idealizado para aquele ambiente.

Alinhado com esse raciocínio, Prena et al (2018) testaram se variações nas condições de JD influenciavam no desempenho cognitivo, utilizando quatro JD distintos, analisando duas

\footnotetext{
${ }^{1}$ Gênero de jogo é uma tipologia de jogos com modelos de interação e dinâmica similares, dentre os mais comuns citam-se ação, aventura, cassino, estratégia, luta, puzzle, tiro, RPG (dramatização) e simulação (Novak, 2010).

${ }^{2}$ Efeito transferência refere-se ao processo de aplicar espontaneamente um conhecimento ou habilidade em contextos diferentes daquele em que foi aprendido.
} 
mecânicas que, em estudos anteriores, demonstraram influenciar positivamente a capacidade de memória de trabalho $^{3}$ : sistema de recompensa e navegação espacial ${ }^{4}$. Contrariamente ao esperado, a presença simultânea dessas duas mecânicas não produziu os melhores desempenhos nos testes de memória dos jogadores. Neste caso, os autores atribuíram o resultado à eventualidade de sobrecarga cognitiva gerada pela interação global com o jogo.

A sobrecarga cognitiva, seja decorrente do excesso de informações ou de dificuldade de assimilação, pode gerar estresse no jogador, reduzindo a capacidade de armazenamento e desempenho da memória de trabalho (Sweller, 2016). Este fator foi testado por Engelhardt et al (2015), cujos experimentos demonstraram que o estado de estresse gerado pela percepção de dificuldade durante o jogo, e não seu conteúdo informacional, reduziu a perfomance em tarefas de controle inibitório, ou seja, criou uma tendência nos jogadores a comportamentos impulsivos, em situações logo após o jogo.

Os achados apontados - a proposta de desconstrução dos jogos, consideração dos aspectos do design e carga cognitiva percebida - sugerem que a análise do potencial cognitivo dos JD não somente é complexa, mas é suscetível a vieses quando não utilizado o mesmo JD (com as mesmas condições) nos experimentos, vista a infinidade de combinações que os elementos de jogos possibilitam construir.

Além de relações causais e sistema de recompensa citados, outros elementos compõem a mecânica dos JD, como o tempo para execução dos objetivos, níveis de dificuldade, desafios e as ações e interações que o jogo permite (Novak, 2010); estruturados para promover a sensação de imersão, interatividade e engajamento do jogador (Westera et al, 2008). Existem diversas definições e taxonomias para mecânica dos JD, umas entendendo-as como combinação de elementos de jogabilidade, outras distinguindo entre regras de objetivos e regras de manipulação de objetos (Djaouti et al, 2008 apud Arnab et al, 2014), mas, em essência, as definições estão associadas com a ideia de que as mecânicas são um conjunto de características que estabelece as regras e as condições que o jogador poderá experimentar (Iuppa \& Borst, 2010).

$\mathrm{Na}$ tentativa de configurar uma conexão entre JD e aprendizado, Arnab et al (2014) desenvolveram o modelo LM-GM (learning mechanics - game mechanics) para análise e construção do design de JD sérios, baseando-se no pressuposto que o aprendizado é experiencial e, no ambiente dos JD, é obtido pela mecânica do jogo. O modelo consiste num mapeamento descritivo-teórico de princípios pedagógicos de aprendizagem, que chamaram de mecânica de aprendizado (participação, observação, instrução, demonstração, etc) e elementos de jogabilidade (regras, níveis, feedback, cooperação, informação em cascata, etc), nomeados como mecânicas de jogos. O modelo LM-GM não contempla mecânicas relacionadas com as regras de manipulação de objetos, bem como, análise dos processos cognitivos que suportam as ações do jogador, situando a ênfase do modelo nos aspectos pedagógicos.

O panorama apresentado demonstra como a análise de um JD é ainda um campo exploratório, complexo e multivariado, cabível em diferentes referenciais teóricos e níveis de profundidade (camadas avaliativas). Este artigo enfoca os aspectos cognitivos de alto nível na interação jogo-jogador e propõe um modelo para rastrear atributos de funções executivas, um grupo de funções cognitivas de alto nível, nas mecânicas de JD e nos elementos de level design utilizados na graduação da complexidade do jogo.

\footnotetext{
${ }^{3}$ Tipo específico de memória utilizada durante a execução de tarefas e que possibilita a pessoa lembrar as etapas já concluídas, em curso e pendentes. A memória de trabalho está contida na família das FE (Diamond, 2013).

${ }^{4}$ Sistema de recompensa refere-se a bonificações ofertadas ao jogador por seus esforços, dentre eles, pontos, vidas, poderes, munição, moedas e desbloqueio de ambientes ou fases. Já a navegação espacial refere-se ao deslocamento tridimensional no ambiente do jogo (Novak, 2010).
} 
Argumenta-se que a mecânica de JD está relacionada com a ação orientada do jogador e por tal, requer habilidades em FE. Além disso, as estratégias de level design de JDs modelam a dificuldade do jogo, fator relacionado com a carga cognitiva percebida pelo jogador com impacto nas FE. Ressalta-se que fogem ao escopo desta pesquisa os JD do tipo multiplayer, pervasivos, locativos (orientados por geolocalização), colaborativos e cooperativos.

Para facilitar a compreensão do leitor quanto ao modelo proposto, este artigo se desenvolverá conforme o processo de construção, apresentando os alicerces conceituais sobre FE e JD nas seções 2 e 3, respectivamente, seguido do protocolo metodológico (seção 4) que levou a colação entre FE, mecânicas de JD e level design. Os resultados obtidos encontram-se na seção 5 e a modelagem desses dados é discutida nas seções 6 e 7, culminando no Modelo Cognitivo de Interação entre Jogo-Jogador (IcJJ), apresentado na seção 8.

\section{Funções Executivas (FE)}

Para viabilizar a interação da pessoa com o ambiente, o cérebro dispõe de mecanismos que integram informações perceptivas do ambiente presente com informações de experiências passadas (memórias), combinando-as para formar novos aprendizados, num processo iterativo, progressivo e associativo (Gazzaninga et al, 2006; Zelazo et al, 2016). A recorrência nas experiências vivenciadas fortalece o circuito associado àquelas informações (rede neural) e se constitui num processo automático que possibilita rapidez na tomada de decisão, exigindo menos atenção e aumentando a responsividade (Gazzaninga et al, 2006). No entanto, quando a pessoa se depara com situações inesperadas ou totalmente novas, esse "programa" pode não ser eficaz ou apropriado, o que exige o recrutamento de um tipo diferente de processamento das informações, mais controlado e que requer maior nível de atenção (Diamond, 2013).

Nesta situação, cujos problemas ou objetivos não são triviais, é necessário administrar vários processos que ocorrem em paralelo e simultaneamente, a citar: inibir a tendência natural de uma resposta, qualificar a relevância das informações, formular um plano sequenciando as ações, dispor de estratégias adaptativas e manter a atenção direcionada para controlar as respostas em consonância com os objetivos pretendidos - capacidades cognitivas estas denominadas de Funções Executivas (Katz, 2008).

\subsection{Composição das Funções Executivas}

As Funções Executivas (FE) são funções mentais responsáveis pela autorregulação do comportamento e gerenciamento da atenção (Gazzaninga et al, 2006; Katz, 2008; Diamond, 2013) e por tal, possuem relação direta com o sucesso escolar, profissional e social (Diamond, 2013; Zelazo et al, 2016), podendo predizer o desempenho em matemática e linguagem (Duncan et al, 2007; Nouwens et al, 2016).

As FE são constituídas de três funções básicas, não hierárquicas: controle inibitório, memória de trabalho e flexibilidade cognitiva. Estas funções fundamentam outras funções cognitivas de alto nível, por exemplo, planejamento cognitivo e raciocínio lógico (Diamond, 2013), iniciativa, julgamento social, autoconsciência e senso crítico (Katz, 2008). Comportamentos relativos à disciplina, flexibilidade para aprender, tolerância à frustração e controle do esforço, também estão relacionados com a habilidade em FE (Zelazo et al, 2016).

\subsubsection{Controle Inibitório}

Controle inibitório é a denominação da função de gerenciar a propensão de resposta a um estímulo e controlar fatores de interferência (Diamond, 2013). Está associado à tomada de 
decisão (ir/não ir), controle da ação impulsiva sem reflexão, persistência na tarefa mesmo diante de situações frustrantes (erros e dificuldades), ação/reação oportuna, autocontrole diante vontades, desejos ou curiosidades que atraem atenção e prejudicam a execução da tarefa/objetivo (Zelazo et al, 2016).

Portanto, o controle inibitório possibilita substituir as respostas habituais (inibir) por novas, controlando as emoções e a atenção (seletiva ou focada), decidindo o momento adequado de agir, por exemplo, numa situação hipotética de jogo com vários objetos na tela, ter de coletar moedas (ir) e desviar de estrelas (inibir), ou, atirar na palavra somente se ela for um verbo (ir para verbo, não ir para os demais).

\subsubsection{Memória de Trabalho}

A memória pode ser entendida como a persistência de um aprendizado, de maneira que a informação esteja armazenada possibilitando evocação futura, o que nos permite formar o conceito das coisas, de si e ter a noção da passagem do tempo (Gazzaninga et al, 2006). A memória de trabalho é um tipo específico de memória, que possui caráter transitório, de curta duração e está condicionada à tarefa ${ }^{5}$ ou objetivo em curso, trata-se da função de representar as informações relevantes e mantê-las evidentes durante a execução da tarefa, para que possam ser manipuladas (Zelazo et al, 2016).

Engloba assim, a capacidade de situar-se num plano de ações (etapas já realizadas e a realizar), traduzir instruções em ações, encontrar conexões entre situações, refletir sobre situações confrontando com experiências passadas, formular e atualizar conceitos (Diamond, 2013), manter em mente as regras e objetivo do jogo enquanto o joga. Por estas características, a memória de trabalho também é denominada de memória processual ou operacional e por sua capacidade de armazenamento limitada, relaciona-se com o conceito de carga cognitiva da tarefa ou carga de trabalho (Kirsh, 2000; Sweller, 2016).

\subsubsection{Flexibilidade Cognitiva}

A capacidade de pensar uma situação ou objeto por diversas perspectivas - espacial, conceitual, social - corresponde à função da flexibilidade cognitiva que, como o nome sugere, possibilita fazer suposições, modificar regras ou padrões de pensamento/comportamento, se ajustar às demandas, aproveitar oportunidades e recriar cenários (Diamond, 2013, Zelazo et al, 2016).

A flexibilidade cognitiva também envolve tomada de decisão, mas diferentemente do controle inibitório, reflete condições complexas que exigem análise (não somente ação/reação), possibilitando transitar entre tarefas simultâneas e alternar entre regras. A dificuldade em flexibilidade cognitiva é observada quando a pessoa tende a perseverar na mesma resposta (aprendidas ou expostas) mesmo diante de negativas, ou não conseguindo desprezar hipótese, previamente reforçada, para descobrir nova regra mais apropriada (Gazzaninga et al, 2006).

\subsection{Construindo a Complexidade em Funções Executivas}

Equilibrar a demanda cognitiva é um fator estratégico para o aprendizado (Pass et al, 2003), porque a percepção de facilidade e dificuldade (nos sentidos extremos) relaciona-se com áreas do cérebro ligadas com as emoções, requerendo esforço adicional para a pessoa manter-se atenta e direcionada para atingir os objetivos quando em situações percebidas como desagradáveis ou difíceis (Howard-Jones, 2014).

\footnotetext{
${ }^{5}$ Neste artigo o termo "tarefa" será utilizado como sinônimo de qualquer etapa ou atividade, simples ou complexa, a ser executada. Por exemplo, redigir um bilhete, acionar o computador, praticar um esporte, comprar um conjunto de itens de uma lista, aprender um conceito novo, lançar bombas contra um inimigo ou resolver um caça-palavras.
} 
Por consequência, a quantidade e natureza das informações que precisam ser manipuladas e gerenciadas, interferem no grau de complexidade e/ou na dificuldade percebida durante a execução da tarefa e no fluxo do aprendizado, visto que os processos mentais estão interligados e são dependentes da habilidade da pessoa para aquela tarefa específica (Kirsh, 2000). Dentre os aspectos constituintes de uma tarefa que podem ser manipulados e interferem em seu grau de complexidade, encontram-se (Katz, 2008): (a) quantidade e variabilidade de elementos a serem recordados (evocados) ou capturados; (b) ausência ou presença de distração durante a execução da tarefa (situações propositadas que dificultam manter-se focado ou presença de ruído ${ }^{6}$ ); (c) qualidade da informação (verbal, visual, espacial) explícita e implícita, podendo requerer deduções ou induzir ações; (d) necessidade de conhecimento prévio; (e) disponibilidade de recursos, situações de restrição ou variabilidade que exigem gerenciamento e tomada de decisão; (f) nível e quantidade de ordenação de etapas ou passos necessários para execução da tarefa e (g) presença ou ausência de pistas cognitivas, ou seja, de dicas ou situações que reforçam o objetivo para reduzir a carga de trabalho (memória).

As técnicas que visam aprimorar as FE buscam subdividir as tarefas ou atividades em pequenas etapas, para modelar a carga cognitiva (quantidade de informações a serem gerenciadas simultaneamente), de modo a favorecer que os objetivos sejam alcançados (Krause et al, 2019b) e, progressivamente, o melhor resultado possível seja conquistado. Dito de outra forma, essas técnicas visam treinar o cérebro a manter-se focado na tarefa em curso ou meta por exemplo, estudar para uma prova, redigir um texto, acordar cedo, concluir uma jogada, resistir ao doce (dieta) - apesar dos "inputs" ambientais (barulho, temperatura, oportunidades, desconforto) e emocionais (frustração, preguiça, medo, desejo, sono, cansaço) contrários ao sucesso do objetivo.

\section{$3 \quad$ Jogos Digitais (JD)}

A ideia base de um JD consiste em possibilitar que os jogadores interajam com o sistema a fim de resolver um conflito artificial, baseado em regras que delimitam o comportamento e direcionam as ações para resolução do conflito (Salen \& Zimmermann, 2012). A simples presença de um conflito não é o que garante a diversão e atratividade de um JD, mas o conjunto de elementos que lhe conferem a imersão e diversão, dentre os quais aspectos estéticos; modos de interatividade; interface e elementos de jogabilidade (Cox \& Bittencourt, 2017). Somam-se ainda, os recursos tecnológicos delimitados pela plataforma de entrega do jogo (Chandler, 2009; Novak, 2010) e o propósito de construção (Iuppa \& Borst, 2010). A Figura 1, baseada em Novak (2010), Iuppa \& Borst (2010) e Heintz \& Law (2015); apresenta uma visão geral dos elementos do design de JD e que, combinados, formam sua diversidade tipológica.

\footnotetext{
${ }^{6}$ Ruído são situações ambientais despropositadas e que podem gerar distração (perda do foco ou atenção), por exemplo, pessoas conversando, objetos que caem ao chão, interrupções (pergunta, telefonema) ou intercorrências (falha no funcionamento do dispositivo, queda da energia elétrica, falta de um dos objetos/materiais necessários para execução da atividade).
} 


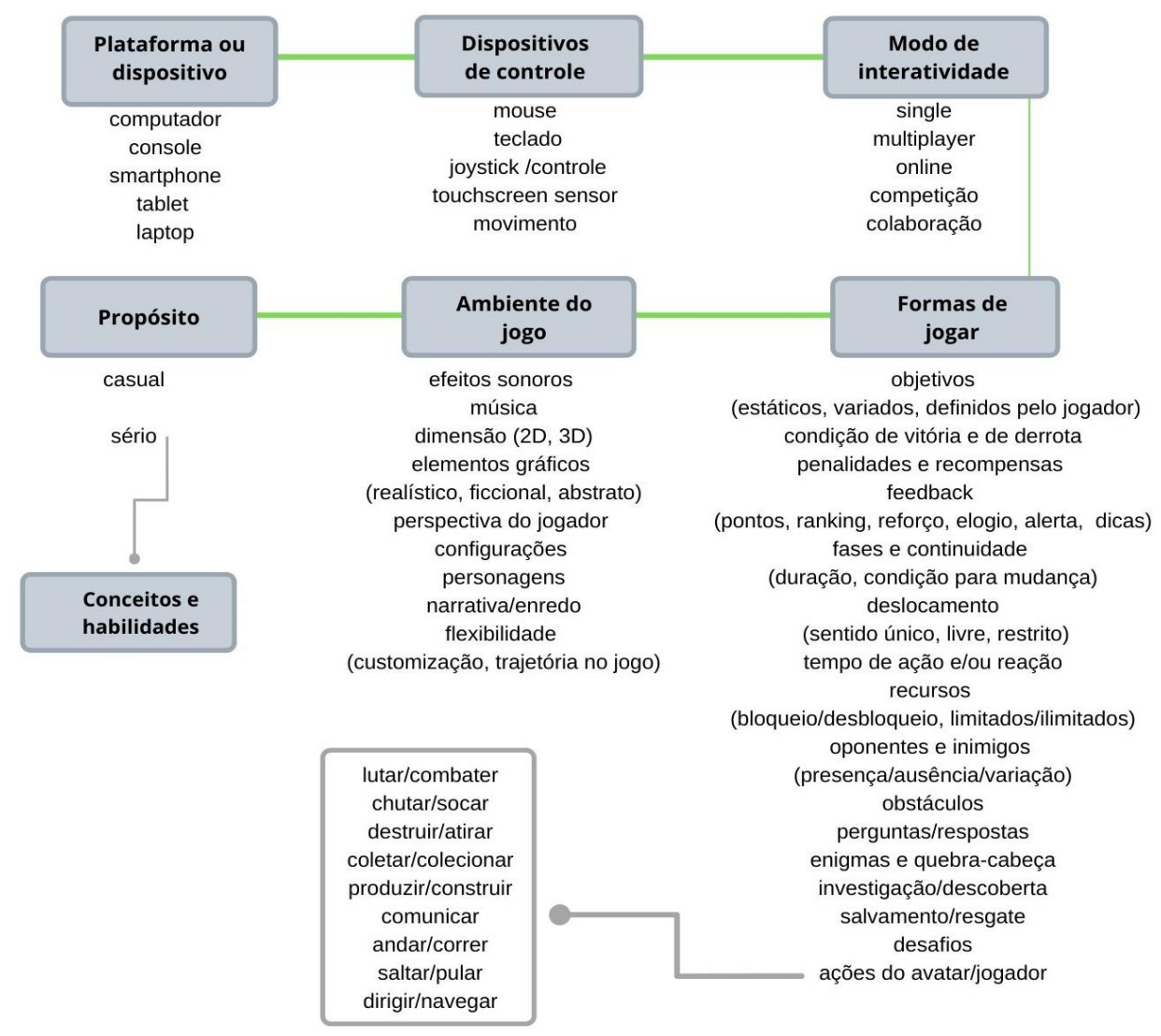

Figura 1: Elementos de Design de Jogos Digitais.

O propósito de construção dos JD pode diferir em casual, direcionado somente para o entretenimento, e sério, termo que designa JD projetados com intuito de desenvolver ou aprimorar habilidades específicas, integrando os objetivos de aprendizado aos elementos de jogabilidade, mantendo as propriedades de diversão e imersão (Connolly et al, 2012). Estas habilidades referem-se, por exemplo, a contextos de saúde, educação, social e de administração (Rego et al, 2010), no entanto, há JD casuais utilizados para desenvolver habilidades específicas, mesmo este não sendo o intuito inicial do jogo, devido às características de jogabilidade (Mattar, 2010).

Os elementos de jogabilidade refletem o modo como o jogador joga e constrói a sua história no ambiente de jogo (Novak, 2010). Dentre seus elementos, situam-se as mecânicas e o design de níveis de dificuldade, que em conjunto, atuam na interação do jogador com o jogo.

\subsection{Mecânicas de Jogos Digitais}

A mecânica do jogo consiste em ações que o jogador executa ou vivencia, sendo composta por desafios (obstáculos, enigmas, metas); recompensas (pontuação, ganho de itens especiais); esquemas de controle (relacionado aos dispositivos de teclado, mouse, controles); ações do jogador e da manipulação de objetos como correr, saltar, pular, jogar feitiços, dirigir veículos, lutar contra oponente, atirar, identificar itens, coletar objetos, montar quebra-cabeças, observar o entorno, percorrer labirinto, entre tantos outros (Chandler, 2009; Iuppa \& Borst, 2010).

Dormans (2012) explica que os termos "mecânica de jogo" e "regra do jogo" por vezes são utilizados como sinônimos ou ideia de regras. Contudo, a mecânica deve ser mais precisa, envolvendo cálculo matemático e detalhamento dos atributos que compõe essa regra, como exemplifica: 


\begin{abstract}
"as regras de um jogo podem determinar que, em um jogo, as lagartas se movam mais rápido que os caracóis, mas a mecânica explicita a diferença; a mecânica especifica com que rapidez as lagartas se movem e quão rápido os caracóis se movem. A mecânica precisa ser precisa suficiente para programadores de jogos transformá-los em código sem confusão ou para jogadores de jogos executá-los sem falhas; a mecânica especifica todos os detalhes necessários (Adams, Rollings, 2007, p. 43 apud Dormans, 2012, p.6, tradução nossa).
\end{abstract}

$\mathrm{O}$ autor acrescenta que uma mesma mecânica pode ser recriada em contextos de jogos com diferentes artes e mídias, sem ser alterada. Esta mesma ideia é defendida por Iuppa \& Borst (2010), quando afirmam que as mecânicas (regras e ações) são elementos de caráter objetivo que, por preservarem suas características, possibilitam criar diversos jogos alterando apenas elementos estéticos como cenário e característica dos objetos.

As mecânicas do jogo também representam ações direcionadas a objetivos, envolvendo tomada de decisão, planejamento, controle do comportamento e por tal, mostram-se como elementos do design de jogos que mais se aproximam dos constructos das FE e que podem ser analisados ou comparados em diferentes contextos, uma vez que desviar rapidamente de bombas é similar, em termos de mecânica, a desviar rapidamente de zumbis, apesar de tratarem de dois jogos distintos.

\title{
3.2 Design de Níveis de Dificuldade (Level Design)
}

Para criar a harmonia entre a interação das mecânicas com os demais elementos, os desenvolvedores de jogos se aprofundam no estudo da curva do aprendizado (Teoria do Flow), para elaboração de situações de exploração e prática, passagem do tempo e espaço, graduação dos desafios e poder de decisão, construindo assim, a sensação no jogador de progressão no jogo (Iuppa \& Borst, 2010). A Teoria do Flow foi desenvolvida no estudo sobre a felicidade humana (Csikszentmihalyi, 2014) e, em contexto de criação de jogos, serve de embasamento teórico sobre como construir ambientes equilibrados considerando o nível de habilidade do jogador e o nível do desafio a ser enfrentado na tarefa, com intuito de produzir a sensação de controle e alto nível de atenção, ou seja, a sensação de fluxo ou imersão (Leffa \& Pinto, 2014).

O level design (LD), ou design de níveis, refere-se a um conjunto de técnicas que atuam como moderadores da experiência do jogador, criando situações que possibilitem aprimorar o modo de jogar, estruturando em subdivisões lógicas, unificando e relacionado as etapas com os demais elementos do ambiente do jogo (Novak, 2010). Estas subdivisões - fases e níveis - são construídas pela manipulação de objetivos e metas, status de progressão (pontuação, vidas), alteração de cenário, variações nas características e quantidades dos objetos, quantidade de desafios e descobertas, duração (da ação ou nível) e ritmo do jogo.

O LD modela a dificuldade do jogo em cada nível e fase e, por conseguinte, interfere na modelagem da complexidade da tarefa ou carga cognitiva do jogo. Curiosamente, a mesma Teoria do Flow utilizada no LD de JD é aplicada para elaborar a graduação da complexidade de atividades utilizadas no âmbito da habilitação/reabilitação cognitiva, área maior que contempla as FE (Katz, 2008).

\section{$4 \quad$ Metodologia}

A metodologia para construção de um modelo para evidenciar atributos cognitivos de alto nível na interação jogo-jogador está baseada em ciclos iterativos, visando à adequação da comunicação do seu conteúdo para especialistas e não especialistas em JD. Destes ciclos, três serão relatados neste artigo. O primeiro buscou estabelecer a relação entre FE e JD a partir da 
literatura e pesquisas já realizadas por outros autores no campo da neurociência cognitiva e computação aplicada; o segundo, de caráter exploratório, objetivou avaliar a linguagem (comunicação) do modelo proposto quanto à descrição das mecânicas de JD e componentes de $\mathrm{FE}$, por meio de um workshop ofertado a pessoas com interesse no tema de JD e/ou FE. O terceiro, semelhante ao primeiro, buscou suporte na literatura para complementar e aprofundar a relação das FE com JD, desta vez incluindo o projeto de level design.

\subsection{Estabelecimento da Relação entre Funções Executivas e Jogos Digitais}

Foi estabelecida uma relação conceitual entre FE e JD a partir da literatura, apesar de que não há um pensamento hegemônico para a terminologia e composição de FE, taxonomia de JD e de mecânicas de JD. Desta forma, adotou-se o seguinte protocolo, com $E_{n}$ representando cada etapa:

$E_{1}$. Caracterização conceitual das FE e identificação dos termos sinônimos na literatura relacionada (neurociência cognitiva, neuropsicologia e reabilitação cognitiva);

$E_{2}$. Caracterização conceitual dos $J D$, com ênfase nos elementos de jogos de mecânica e estratégias de level design, identificando termos sinônimos (literatura de games e jogos sérios);

A partir da adoção terminológica, analisou-se um conjunto de artigos $(\mathrm{n}=32)$ obtidos em mapeamento sistemático que utilizou o termo de busca "executive function AND game" (Krause et al, 2018). Cada artigo foi lido na íntegra, extraindo-se os dados: avaliadas);

E3. Conceito e componentes de FE abordados no estudo (variáveis manipuladas ou

E. Descrição dos jogos aplicados no experimento (ações apresentadas aos jogadores, variáveis manipuladas no jogo);

$E_{5}$. Justificação da escolha dos jogos e argumentos de correlação com as FE;

$E_{6}$. Propósito da pesquisa (avaliar, treinar, descrever);

P7. Caracterização dos sujeitos da pesquisa (amostra);

$E_{8}$. Técnicas aplicadas para validar os dados (testes cognitivos, exames neurofuncionais por imagens, testes funcionais, presença de grupo controle);

E9. Desfecho das pesquisas (evidências).

Para os artigos cujas informações sobre o JD ou FE de estudo não eram explícitas, foram acrescentadas as etapas:

$E_{10}$. Identificação do contexto e construção do experimento com relação à questão de pesquisa e composição dos testes cognitivos ou neurais de avaliação;

$E_{11}$. Pesquisa de entorno buscando por publicações anteriores e posteriores dos autores utilizando o mesmo JD elou pesquisa sobre os JD utilizados nos experimentos;

Por fim, concluindo o primeiro ciclo, estabeleceu-se a relação entre as variáveis de estudos - $\left(V_{a}\right)$ componentes de FE e $\left(V_{b}\right)$ mecânicas de JD - por meio das seguintes estratégias:

$E_{12}$. Transformar as descrições dos $J D\left(E_{4}\right)$ em expressões verbais, denominadas de mecânicas Mn;

$E_{13}$. Identificar e quantificar a recorrência das relações de componentes de $F E\left(V_{a}\right)$ versus mecânica de $J D\left(V_{b}\right)$;

\subsection{Workshop}

Identificadas as mecânicas de JD (Mn) e relacionadas com os componentes das FE (controle inibitório, memória de trabalho e flexibilidade cognitiva), em continuação à etapa anterior (Krause et al, 2019a), ofertou-se um workshop para avaliar a comunicação (linguagem e 
apresentação) das mecânicas identificadas e a percepção de especialistas e não-especialistas em JD e/ou FE, quanto a relação entre estas duas variáveis. O workshop foi ofertado para duas turmas (denominadas de $\mathrm{T}_{1}$ e $\mathrm{T}_{2}$ ), com duração de três horas, assim distribuídas:

$W_{1}$ : Apresentação conceitual de FE e JD;

$W_{2}$ : Registro pelos participantes dos componentes de FE relacionados a cada mecânica contida numa listagem;

$W_{3}$ : Discussão sobre as percepções dos participantes (comunicação das mecânicas e argumentação da relação com os componentes executivos);

W4: Avaliação do workshop.

O workshop respeitou as condições éticas de pesquisa, mantendo o anonimato e autorização dos participantes por meio de Termo de Consentimento de Participação em Pesquisa Científica. Os dados coletados em cada turma foram aglutinados, configurando a percepção da relação FE-Mn para cada mecânica. Após, os resultados foram confrontados, sendo considerada como evidência, a relação indicada em todos os grupos de resultados: revisão de Krause et al (2019a) e percepção das turmas $\mathrm{T}_{1}$ e $\mathrm{T}_{2}$.

\subsection{Incorporação do Level Design}

Para estabelecer a relação entre as variáveis componentes de FE $\left(V_{a}\right)$ e estratégias de level design $\left(V_{c}\right)$, sobre o mesmo conjunto de artigos (Krause et al, 2018) utilizados no primeiro ciclo investigativo, aplicou-se as seguintes ações:

$L_{1}$. Identificar as variáveis manipuladas para construir a complexidade do jogo, denominados de Dn;

$L_{2}$. Identificar e quantificar a recorrência das relações de componentes de $F E\left(V_{a}\right)$ versus estratégias de level design $\left(V_{c}\right)$.

Os dados coletados foram acrescidos aos resultados já tabulados de cada artigo (primeiro ciclo), estabelecendo um quadro de relações entre funções executivas e descritores de level design (FE-Dn).

\section{$5 \quad$ Resultados}

O estudo sobre os JD e sobre as FE pode ocorrer em diferentes camadas e por diversas áreas do conhecimento, em consequência, as pesquisas não são hegemônicas com relação aos termos relativos às duas variáveis em questão. A Revisão da Literatura (etapas $\mathrm{E}_{1}$ e $\mathrm{E}_{2}$ ) possibilitou a construção de um quadro para os termos envolvidos nesta pesquisa (Quadro 1), considerados como sinônimos durante a extração dos dados.

Quadro 1: Glossário de sinônimos adotados na pesquisa

\begin{tabular}{|c|c|l|}
\hline \multirow{2}{*}{$\begin{array}{c}\text { Controle } \\
\text { inibitório (CI) }\end{array}$} & $\begin{array}{l}\text { inibição, inibição da resposta, autocontrole, controle da atenção, controle de interferência, } \\
\text { atença seletiva, autorregulação }\end{array}$ \\
\cline { 2 - 4 } & $\begin{array}{c}\text { Memória de } \\
\text { trabalho (MT) }\end{array}$ & $\begin{array}{l}\text { memória sequencial, memória processual, memória operacional, memória de trabalho } \\
\text { visoespacial. }\end{array}$ \\
\cline { 2 - 4 } & $\begin{array}{c}\text { Flexibilidade } \\
\text { cognitiva (FC) }\end{array}$ & $\begin{array}{l}\text { criatividade, alternância entre tarefas, flexibilidade de atenção, fluidez de pensamento, } \\
\text { pensamento fluído, deslocamento, multitarefa, dupla-tarefa. }\end{array}$ \\
\cline { 2 - 4 } & $\begin{array}{c}\text { Função } \\
\text { executiva geral } \\
\text { (FE) }\end{array}$ & $\begin{array}{l}\text { Habilidades cognitivas superiores, controle executivo, planejamento, estratégia, lógica, } \\
\text { raciocínio, resolução de problemas, funções cerebrais superiores, funções cognitivas de alto } \\
\text { nível. }\end{array}$ \\
\hline
\end{tabular}




\begin{tabular}{|c|c|c|}
\hline 厸 & Videogame & $\begin{array}{l}\text { jogo eletrônico, jogo digital - com ou sem mundo virtual (descrito como jogo em 3D), } \\
\text { simulação; jogos cujo movimento corporal do jogador restringe-se ao digital/manual }\end{array}$ \\
\hline 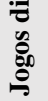 & $\begin{array}{l}\text { Exergame } \\
\text { EG) }\end{array}$ & $\begin{array}{l}\text { jogo ativo, videogame interativo - com ou sem mundo virtual, exergame para MMSS } \\
\text { (membros superiores), jogo com realidade aumentada (mas descrito como movimento corporal } \\
\text { amplo para ações do jogador na projeção em tela) }\end{array}$ \\
\hline
\end{tabular}

\subsection{Perfil Geral das Pesquisas}

O conjunto de artigos selecionados do mapeamento de Krause et al (2018), se constitui de 31 trabalhos que articularam algum nível de relação entre FE e JD, envolvendo diversas faixas etárias, entre 4 e 80 anos de idade. A faixa etária mostrou-se independente do componente executivo estudado.

Quanto aos objetivos de pesquisa, estes se distribuíram na investigação do efeito do treinamento em habilidades executivas por meio de JD (45\%), na validação dos JD enquanto instrumento para avaliação de FE (22\%), na análise do impacto do uso corrente dos JD no desempenho executivo (19\%) e na investigação do funcionamento neural das FE usando os JD para ativação cognitiva (13\%).

Exceto por dois estudos, realizados online e por instalação do jogo no computador doméstico, os experimentos relatados, no conjunto dos artigos selecionados, foram presenciais. A expectativa inicial era por pesquisas envolvendo manipulação de elementos de JD para estudo de efeito sobre as FE, contudo, visto ao baixo número de artigos com esta característica, optouse por incluir os demais artigos na Revisão Sistemática, organizando-os em grupos conforme as características do design de pesquisa, com enfoque na manipulação dos elementos de JD, com intuito de identificar padrões de relações (JD x FE) e analisar os resultados obtidos (força do resultado), processo que resultou em cinco perfis de pesquisa descritos abaixo e condensados no Gráfico 1.

Gráfico 1: Distribuição conforme manipulação dos JDs no experimento
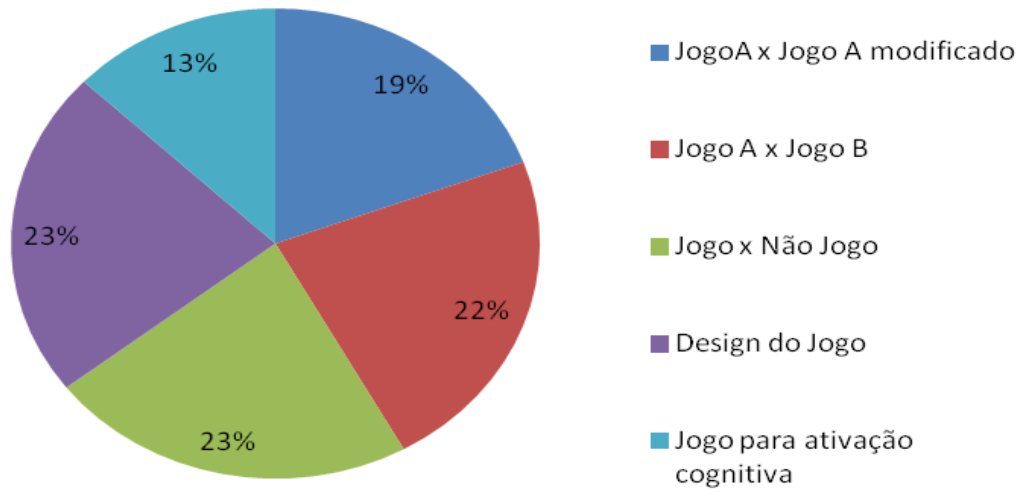

(a) Jogo A $x$ Jogo A modificado: pesquisa experimental exploratória, com grupo controle, voltada para identificação de recursos potenciais para incremento nas FE por meio de manipulação de elementos de um mesmo JD, por exemplo, velocidade ou quantidade de objetos para desviar o foco do jogador e restrição de tempo de ação;

(b) Jogo A x Jogo B: pesquisa experimental exploratória, visa analisar os gêneros de JD (ação, aventura, puzzle, ritmo/dança, tiro em primeira pessoa) e os componentes executivos requeridos (não discutindo necessariamente mecânicas);

(c) Jogo $x$ Não jogo: tipo experimental comparativo, composto por pesquisas que compararam técnicas ou abordagens para melhorar a performance cognitiva ou motora, 
considerando os JD como recurso de intervenção. Neste tipo de pesquisa os elementos do jogo não são alterados, apenas o contexto, como ao comparar o impacto nas $\mathrm{FE}$ de atividade física isolada em contraponto ao uso de exergame ou para identificar desempenho em teste cognitivo entre jogadores e não jogadores;

(d) Processo de design do jogo: de caráter descritivo, este tipo de artigo visa divulgar o processo de construção de JD voltado à avaliação ou treino executivo; sua inclusão se justifica pela argumentação na elaboração do design, desenvolvimento de requisitos e parâmetros;

(e) Jogo para ativação cognitiva: o JD não é variável foco da pesquisa, mas utilizado como artefato para ativar áreas cerebrais que contemplam as $\mathrm{FE}$ e supostamente são prejudicadas devido a hábitos ou outras interações, por exemplo, estudo sobre efeito da interrupção do sono em crianças (Colonna et al, 2018) ou impacto do uso de álcool combinado com estresse em universitários (Goldstein et al, 2016). A inclusão deste grupo foi mantida devido a escolha dos JD para aplicação nos experimentos não ser arbitrária.

Relativo à mensuração e validação dos resultados das pesquisas, não foi encontrado prevalência de técnica, sendo citados 49 métodos distintos, por exemplo, avaliação neuropsicológica (Gamito et al, 2013; Kayama et al, 2014; Goldstein et al, 2016; Klein et al, 2017; Li et al, 2018), avaliação ecológica ou funcional (Burdéa et al, 2014; Flynn et al, 2014), exame neurológico por imagem (Baniqued et al, 2015; Liu et al, 2015; Schattin et al, 2016; Mondéjar et al, 2016; Anderson-Hanley et al, 2018), entrevista com especialistas (Schoene et al, 2015; Baranyi et al, 2016; Martinez-Pernia et al, 2017), questionários de usabilidade e aceitabilidade de mídia (Yeh et al, 2013; Engelhard et al, 2015; Gray et al, 2015; Kuhn et al, 2018), desempenho no jogo (McKenna et al, 2014; Smittenaar et al, 2015; Avila-Pesantez et al, 2018; Colonna et al, 2018) e efeito de transferência da habilidade adquirida no jogo para tarefas externas a ele (Oei et al, 2014; Dovis et al, 2015; Parong et al, 2017; Schoat et al, 2017) .

\title{
5.2 Relações identificadas
}

A extração e aglutinação das mecânicas de JD, contidas e/ou manipuladas nos jogos utilizados nos experimentos, baseou-se na descrição apresentada pelos autores sobre a tarefa a ser executada pelo jogador, conforme exemplificado no trecho a seguir:

\begin{abstract}
O trabalho do jogador era satisfazer a sede e a fome dos alienígenas, atirando alimentos e bebidas de um distribuidor na parte inferior da tela. Os jogadores foram instruídos [...] por exemplo, alienígenas vermelhos estão com fome e alienígenas azuis estão com sede, $[. .$.$] "agora alienígenas azuis estão com fome e alienígenas vermelhos$ estão com sede". Outro tipo de mudança ocorreu quando a regra mudou com base em uma propriedade diferente dos alienígenas (por exemplo, uma regra baseada no número de olhos em vez de cores) " (Parong et al, 2017, p. 148, tradução e grifo nosso).
\end{abstract}

Esta descrição indica que a tarefa imposta ao jogador consistia em relacionar elementos alvo (aliens) a objetos (alimentos, bebidas) mediante regras associativas que alternavam ou invertiam entre as fases. A pesquisa de Parong et al (2017) citada, centrou-se no estudo do componente executivo de flexibilidade cognitiva ou controle da atenção durante a alternância entre tarefas. Para verificar o efeito provocado pelo uso do JD neste componente, os autores utilizaram dois testes cognitivos computadorizados: (i) dada uma imagem, esta deveria ser associada à outra pelas dimensões cor ou forma, conforme a ordem apresentada; (ii) um par de letra-número era apresentado em um dos quatro quadrantes da tela (no sentido horário), de modo que a pessoa deveria decidir se o número era par ou ímpar (quando no quadrante superior esquerdo e direto) ou se era vogal ou consoante (quando no quadrante inferior direito e esquerdo). Estes dois testes são aplicados para mensuração de flexibilidade cognitiva. Para este contexto, constituiu-se a relação de componente de FE de "flexibilidade cognitiva" com a 
mecânica"alternar ações conforme regras modificáveis ou conflitantes (inversas)".

Esta estratégia de extração resultou na identificação de 22 mecânicas de JD relacionadas à FE, com maior volume de pesquisas direcionadas para o estudo das FE de forma global, seguido de interesse no componente de controle inibitório, memória de trabalho e flexibilidade cognitiva, conforme descrito no Quadro 2 (Krause et al, 2019a).

Ainda, exemplificando a construção relacional, cita-se a pesquisa de McKenna et al (2014). Estes autores desenvolveram um JD, baseado no teste Torre de Hanoy que mensura a habilidade em flexibilidade cognitiva, para um experimento comparativo do jogo na versão videogame e exergame, direcionado à população infantil. O jogo consistia de trajetos de lírios sobre os quais a criança deveria percorrer a trajetória, buscando o menor caminho possível, ou seja, o jogador deveria criar mentalmente as diferentes possibilidades para então tomar a decisão e planejar as ações. Em termos de resultado, os pesquisadores identificaram que a versão videogame do JD promoveu melhor desempenho das crianças nos testes cognitivos de flexibilidade cognitiva. Os autores atribuíram este achado a possibilidade da versão exergame ter promovido sobrecarga cognitiva ao envolver coordenação motora associada com os aspectos

Quadro 2: Descrição e distribuição das mecânicas de JDs por componente de FEs

\begin{tabular}{|c|c|c|}
\hline & Ações/Mecânicas associadas à função executiva & Qtde \\
\hline \multirow{15}{*}{ 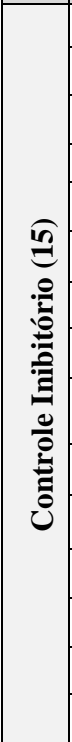 } & M1: Reagir sob ação rápida & 9 \\
\hline & M2: Selecionar, escolher entre os distradores (tomada de decisão) & 6 \\
\hline & M3; Mirar, atirar, destruir & 4 \\
\hline & M4: Agir e reagir conforme regra ativa ou inibitória (se x faço, se y não faço) & 4 \\
\hline & M5: Suspender ação por período de tempo e acioná-la posteriormente & 3 \\
\hline & M6: Saltar, pular, desviar obstáculos & 2 \\
\hline & M7: Navegar desviando de obstáculos ou distradores enquanto captura alvos & 2 \\
\hline & M8: Alternar ações, movimentos, padrões & 2 \\
\hline & $\begin{array}{l}\text { M9: Resistir a opções de domínio para executar tarefas necessárias (resistir à tentação de repetir ou fazer aquele percebido } \\
\text { como mais fácil) }\end{array}$ & 1 \\
\hline & M10: Repetir movimentos do avatar, imitar sequência motora & 1 \\
\hline & M11: Ser induzido a manter ações e repentinamente ter de suspendê-la por um tempo, voltando a ação anterior induzida & 1 \\
\hline & M12: Comutar lados do corpo (correspondência de ação com parte do corpo) & 1 \\
\hline & M13: Parear informação (tem/não tem), observar diferenças entre telas & 1 \\
\hline & M14: Recordar o que precisa ser selecionado (itens) & 1 \\
\hline & M15: Planejar as ações antes de executá-las & 1 \\
\hline \multirow{10}{*}{ 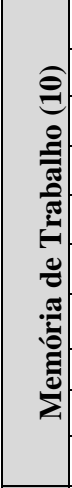 } & M16: Recordar sequência de tarefas (passos, objetivos, missões) a cumprir & 7 \\
\hline & M14: Recordar o que precisa ser selecionado (itens) & 5 \\
\hline & M15: Planejar as ações antes de executá-las (descrever sequência do plano) & 1 \\
\hline & M13: Parear informação (tem/não tem), observar diferenças entre telas & 1 \\
\hline & M17: Alternar ações conforme regras modificáveis ou conflitantes (inversas) & 1 \\
\hline & M18: Resolver e descobrir enigmas ou padrões lógicos & 1 \\
\hline & M19: Ordenar por correspondência a regra que altera a ordem em determinados ciclos & 1 \\
\hline & M8: Alternar ações, movimentos, padrões & 1 \\
\hline & M2: Selecionar, escolher entre os distradores (tomada de decisão) & 1 \\
\hline & M10: Repetir movimentos do avatar, imitar sequência motora & 1 \\
\hline \multirow{5}{*}{ 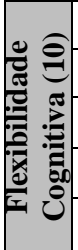 } & M15: Planejar as ações antes de executá-las (buscar melhor solução, caminho) & 5 \\
\hline & M17: Alternar ações conforme regras modificáveis ou conflitantes (inversas) & 4 \\
\hline & M18: Resolver e descobrir enigmas ou padrões lógicos & 4 \\
\hline & M8: Alternar ações, movimentos, padrões & 3 \\
\hline & M20: Rotacionar peça mentalmente e encaixar (similar Tetris, quebra-cabeça) & 2 \\
\hline
\end{tabular}




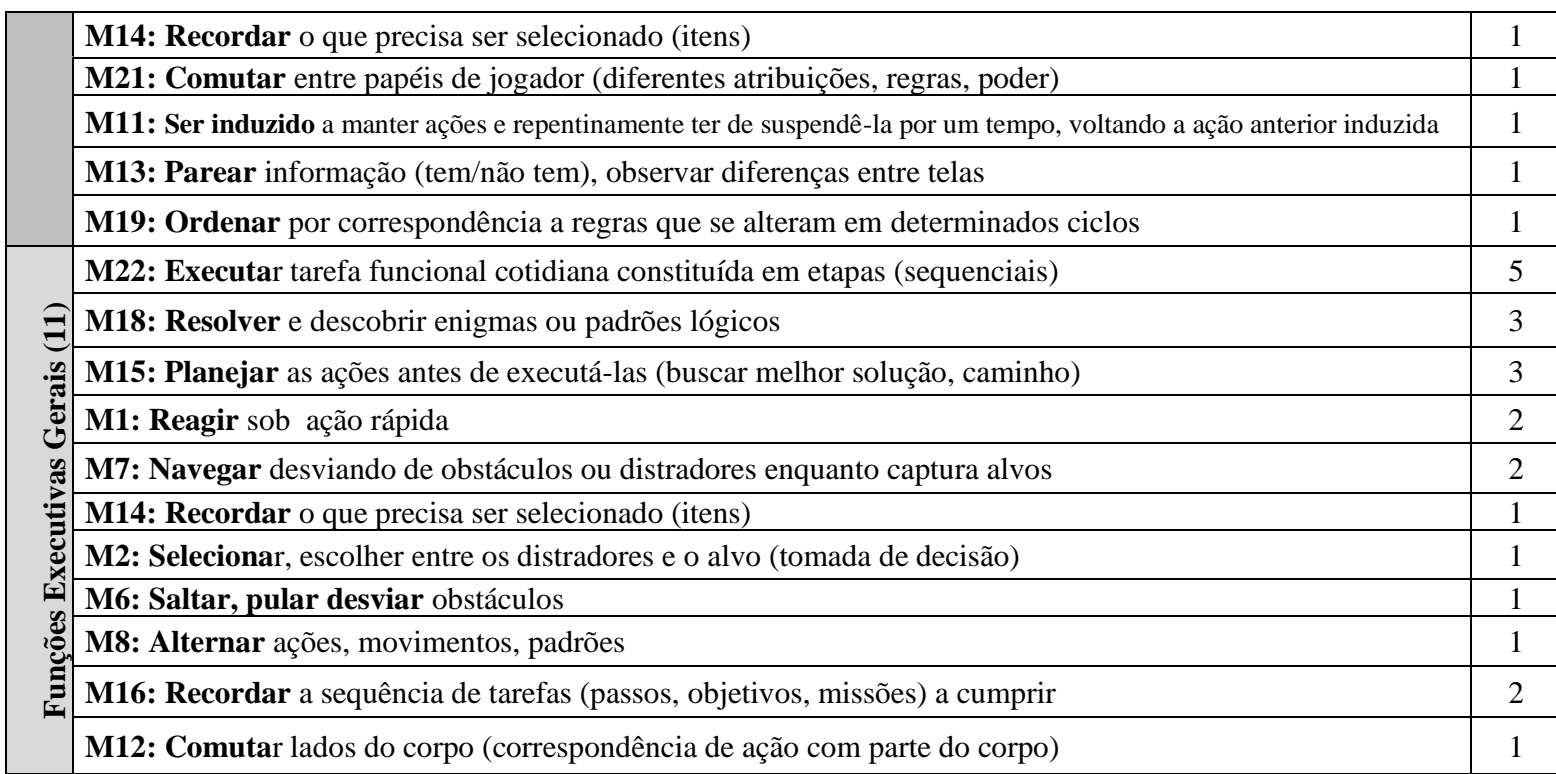

cognitivos. Este experimento reflete a relação da mecânica extraída "Planejar as ações antes de executá-las $\left(\mathrm{M}_{15}\right)$ " com os atributos de flexibilidade cognitiva, relacionados com mudança de perspectiva, alternância entre ações e flexibilidade na elaboração mental de cenários e perspectivas (Diamond, 2013).

Os dois exemplos apresentados, de Parong et al (2017) e de McKenna et al (2014), demonstram que é possível ter um conjunto de mecânicas que trabalham o mesmo componente executivo, por este último estar associado a vários aspectos funcionais ou comportamentais, permitindo sua exploração por diferentes abordagens.

\subsection{Resultados do Workshop}

Participaram do workshop 13 pessoas (idade média de 28,4 anos, 61,5\% mulheres) de diferentes áreas do conhecimento: Pedagogia; Terapia Ocupacional; discentes dos cursos de Ciência da Computação, Tecnologia da Informação, Psicologia e licenciatura em Física e Matemática.

O intuito do workshop foi de identificar a percepção dos participantes quanto à comunicação das mecânicas de JD (linguagem descritiva) e a relação dessas com os componentes de FE, com base nas mecânicas identificadas na Revisão de Literatura (Krause et al, 2019a). O Quadro 3 apresenta a comparação entre os resultados dessa revisão (R) e da percepção das turmas do workshop $\left(\mathrm{T}_{1}, \mathrm{~T}_{2}\right)$ para cada colação mecânica $(\mathrm{Mn})$ e componente executivo: as células coloridas representam a relação apontada $\mathrm{Mn}$ (mecânica de mesmo n) - FE (controle inibitório, memória de trabalho, flexibilidade cognitiva, FE gerais) e a última coluna denominada "Evidência", destaca o resultado coincidente entre os três grupos (R, T1 e T2) em relação à mecânica e a FE correspondente.

Ressalta-se que no workshop não foi dada a opção "funções executivas gerais", estimulando o participante a marcar o(s) componente(s) executivo(s) que julgasse mais relevante ou evidente. Durante a análise dos resultados dos participantes, caso uma mesma mecânica estivesse associada aos três componentes simultaneamente, esta foi considerada como "funções executivas gerais".

Após as discussões dos participantes em duplas e posteriormente com todos, analisando o resultado da avaliação geral do workshop, para estas turmas, observou-se: (a) presença de mecânicas similares que poderiam ser unificadas; (b) a mecânica $\mathbf{M}_{22}$ mostrou-se genérica, passível de subdivisão; (c) necessidade de ampliação das descrições de cada mecânica; (d) dificuldade na diferenciação entre memória de longo prazo e memória de trabalho e (e) 
dificuldade na diferenciação entre controle inibitório e flexibilidade cognitiva. Além disso, percebeu-se que a contextualização das mecânicas, exemplificando em diferentes tipos de JD e a explicação sobre como são construídas as fases e níveis dos jogos, poderia facilitar a avaliação isolada, pelos participantes, dos componentes de FE requeridos em cada mecânica descrita.

Quadro 3: Percepção da relação entre Mecânicas de JD e Componentes de FE

\begin{tabular}{|c|c|c|c|c|c|c|c|c|c|c|c|c|c|}
\hline \multirow[t]{2}{*}{ LISTAGEM DAS MECÂNICAS } & \multicolumn{3}{|c|}{$\begin{array}{l}\text { Controle } \\
\text { Inibitório } \\
\quad \text { (CI) }\end{array}$} & \multicolumn{3}{|c|}{$\begin{array}{c}\text { Memória } \\
\text { de } \\
\text { Trabalho } \\
\text { (MT) }\end{array}$} & \multicolumn{3}{|c|}{$\begin{array}{c}\text { Flexibilida } \\
\text { de } \\
\text { Cognitiva } \\
\text { (FC) }\end{array}$} & \multicolumn{3}{|c|}{$\begin{array}{c}\text { Funções } \\
\text { Executivas } \\
\text { Gerais } \\
\text { (FG) }\end{array}$} & \multirow[t]{2}{*}{$\begin{array}{l}\text { Evi } \\
\text { Dên } \\
\text { cia }\end{array}$} \\
\hline & $\mathbf{R}$ & T1 & $\mathbf{T 2}$ & $\mathbf{R}$ & $\mathbf{T 1}$ & $\mathbf{T 2}$ & $\mathbf{R}$ & T1 & T2 & $\mathbf{R}$ & T1 & T2 & \\
\hline M1: Reagir sob ação rápida & & & & & & & & & & & & & CI \\
\hline $\begin{array}{l}\text { M2: Selecionar, escolher entre os distradores } \\
\text { (tomada de decisão) }\end{array}$ & & & & & & & & & & & & & $\begin{array}{l}\text { CI, } \\
\text { MT }\end{array}$ \\
\hline M3; Mirar, atirar, destruir & & & & & & & & & & & & & CI \\
\hline $\begin{array}{l}\text { M4: Agir e reagir conforme regra ativa ou } \\
\text { inibitória (se x faço, se y não faço) }\end{array}$ & & & & & & & & & & & & & CI \\
\hline $\begin{array}{l}\text { M5: Suspender ação por período e acioná-la } \\
\text { posteriormente (tempo de suspensão maior } \\
\text { que de reação) }\end{array}$ & & & & & & & & & & & & & CI \\
\hline M6: Saltar, pular, desviar obstáculos & & & & & & & & & & & & & CI \\
\hline $\begin{array}{l}\text { M7: Navegar desviando de obstáculos ou } \\
\text { distradores enquanto captura alvos }\end{array}$ & & & & & & & & & & & & & $\begin{array}{l}\text { CI, } \\
\text { FG }\end{array}$ \\
\hline M8: Alternar ações, movimentos, padrões & & & & & & & & & & & & & FC \\
\hline $\begin{array}{l}\text { M9: Resistir a opções de domínio e executar } \\
\text { tarefas necessárias (resistir a repetir/fazer o } \\
\text { mais fácil) }\end{array}$ & & & & & & & & & & & & & CI \\
\hline $\begin{array}{l}\text { M10: Repetir movimentos do avatar, imitar } \\
\text { sequência motora }\end{array}$ & & & & & & & & & & & & & MT \\
\hline $\begin{array}{l}\text { M11: Ser induzido a manter ações e } \\
\text { repentinamente ter de suspendê-la, voltando } \\
\text { a ação anterior }\end{array}$ & & & & & & & & & & & & & $\begin{array}{l}\text { CI, } \\
\text { FC }\end{array}$ \\
\hline $\begin{array}{l}\text { M12: Comutar lados do corpo } \\
\text { (correspondência de ação com parte do } \\
\text { corpo) }\end{array}$ & & & & & & & & & & & & & CI \\
\hline $\begin{array}{l}\text { M13: Parear informação (tem/não tem), } \\
\text { observar diferenças entre telas (similar ao } \\
\text { jogo dos sete erros) }\end{array}$ & & & & & & & & & & & & & MT \\
\hline $\begin{array}{l}\text { M14: Recordar o que precisa ser selecionado } \\
\text { (itens) }\end{array}$ & & & & & & & & & & & & & MT \\
\hline M15: Planejar as ações antes de executá-las & & & & & & & & & & & & & $\begin{array}{l}\text { MT, } \\
\text { FC }\end{array}$ \\
\hline $\begin{array}{l}\text { M16: Recordar sequência de tarefas (passos, } \\
\text { objetivos, missões) a cumprir }\end{array}$ & & & & & & & & & & & & & MT \\
\hline $\begin{array}{l}\text { M17: Alternar ações conforme regras } \\
\text { modificáveis ou conflitantes (inversas) }\end{array}$ & & & & & & & & & & & & & FC \\
\hline $\begin{array}{l}\text { M18: Resolver e descobrir enigmas ou } \\
\text { padrões lógicos }\end{array}$ & & & & & & & & & & & & & $\begin{array}{l}\text { MT, } \\
\text { FC }\end{array}$ \\
\hline $\begin{array}{l}\text { M19: Ordenação por correspondência a regra } \\
\text { que altera (inverte) a ordem em ciclos }\end{array}$ & & & & & & & & & & & & & FC \\
\hline $\begin{array}{l}\text { M20: Rotacionar peça mentalmente e } \\
\text { encaixar (similar Tetris, quebra-cabeça }\end{array}$ & & & & & & & & & & & & & FC \\
\hline $\begin{array}{l}\text { M21: Comutar entre papéis de jogador } \\
\text { (diferentes atribuições, regras, poder) }\end{array}$ & & & & & & & & & & & & & FC \\
\hline
\end{tabular}


M22: Executar tarefa funcional cotidiana constituída em etapas (sequenciais)

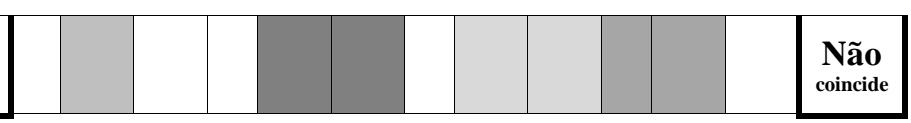

\section{Atributos das Funções Executivas nas Mecânicas de Jogos Digitais}

O primeiro ciclo investigativo resultou em 22 mecânicas de JD relacionadas com os componentes de FE (Krause et al, 2019a). Com intuito de simplificar e diminuir a quantidade de mecânicas rastreadas solicitou-se aos participantes do workshop que observassem similaridade ou aproximações no conjunto das 22 mecânicas. Baseado neste critério, observando as argumentações obtidas no workshop e analisando os verbos ou ações impostas ao jogador, descritas em cada mecânica, foi possível aglutinar algumas delas (Ma, Mb, Mc, Mi) (Figura 2), bem como sugeriu-se o desmembramento para uma mecânica adicional (Me), visto que os atributos da aleatoriedade não transformam-se em microproblemas a serem gerenciados, dentro da ação maior.

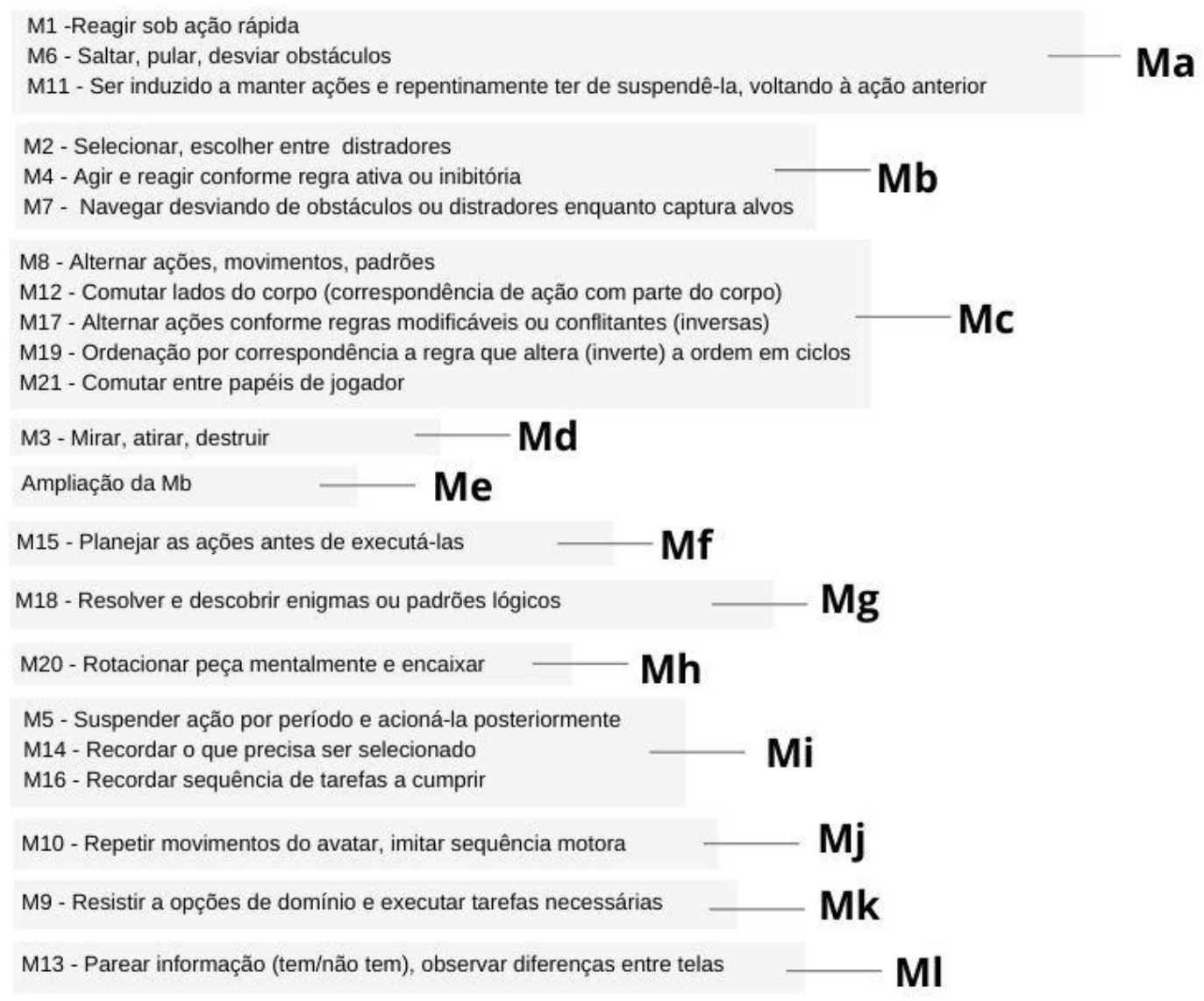

Figura 2: Processo de Aglutinação das Mecânicas de Jogos Digitais

Como cada mecânica estava associada a componentes executivo (Quadro 3), na presença de mais de um componente, este foi incluído. Por exemplo, as relações $\mathrm{M}_{1}-\mathrm{CI}, \mathrm{M}_{6}$-CI e $\mathrm{M}_{11^{-}}$ $\mathrm{CI} / \mathrm{FC}$, formaram a nova mecânica condensada Ma relacionada com os componentes de controle inibitório (CI) e flexibilidade cognitiva (FC). Desta forma, chegou-se a nova configuração, composta por 12 mecânicas relacionadas com as FE (Quadro 4) e que participam do Modelo Cognitivo de Interação Jogo-Jogador (IcJJ) proposto neste artigo.

Este conjunto de mecânicas representa uma proposta em converter para a linguagem de JD as situações que requerem FE, dentre elas, como cita Gazzaninga et al (2006), situações que 
requerem planejamento ou tomada de decisão; que competem com respostas habituais preponderantes; que requerem correção de erros ou resolução de problemas; que se mostram difíceis ou perigosas e quando a informação perceptiva (input) é contraditória, incompatível (padrão em curso), se mostra nova ou não está consolidada na memória de longa duração (bem aprendida).

Quadro 4: Relação entre mecânicas de JD e componentes de FE.

\begin{tabular}{|c|c|c|}
\hline Mecânica $\left(\mathbf{M}_{\mathbf{x}}\right)$ & Descrição & $\begin{array}{c}\text { Função } \\
\text { Executiva }\end{array}$ \\
\hline Ma - Reação rápida & $\begin{array}{c}\text { Saltar, pular entre plataformas; Desviar de obstáculos ou elementos que } \\
\text { interferem na atenção (distração); Ser induzido a manter ações e repentinamente } \\
\text { ter de suspendê-las por um tempo, voltando a ação anterior induzida. Requer } \\
\text { responder rapidamente ao estímulo, sem que precise analisar as consequências } \\
\text { da ação, senso de prontidão para agir diante do estímulo alvo. Por exemplo, se } \\
\text { x, faço. }\end{array}$ & $\begin{array}{l}\text { Controle } \\
\text { Inibitório } \\
\text { Flexibilidade } \\
\text { Cognitiva }\end{array}$ \\
\hline $\begin{array}{l}\text { Mb - Agir e reagir } \\
\text { conforme regra ativa ou } \\
\text { inibitória }\end{array}$ & $\begin{array}{l}\text { Navegar capturando alvos (x) e desviar de obstáculos, inimigos (y); Selecionar } \\
\text { (escolher) elementos alvo entre elementos de distração ou de indução ao erro. } \\
\text { Requer agir conforme duas regras antagônicas, uma positiva e outra negativa, } \\
\text { neste caso, há elemento de restrição da ação. Por exemplo, se x faço (ação e } \\
\text { ganha); se y, não faço (suspensão) e se fizer perco. }\end{array}$ & $\begin{array}{l}\text { Controle } \\
\text { Inibitório } \\
\text { Memória de } \\
\text { Trabalho } \\
\text { FE gerais }\end{array}$ \\
\hline $\begin{array}{l}\text { Mc - Alternar ações } \\
\text { conforme regras } \\
\text { modificáveis ou } \\
\text { conflitantes (inversas) }\end{array}$ & $\begin{array}{l}\text { Aprende padrão de ação e depois esse padrão é alterado (inverte), depende do } \\
\text { fator tempo de aprendizado entre as fases ou níveis; Tarefas que requerem } \\
\text { alternar ações, movimentos ou padrões; Alternar lados do corpo com ação } \\
\text { espacialmente correspondente, por exemplo, apanhar com a mão esquerda } \\
\text { objetos à esquerda da tela e pegar com a mão direita objetos à direita da tela; } \\
\text { Requer modificar os padrões de ação e estratégias para atingir o objetivo devido } \\
\text { alteração na função do personagem. Por exemplo, numa fase o jogador } \\
\text { desempenha papel de chefe de uma empresa e gerenciar pessoas, depois, no } \\
\text { mesmo jogo, passa a ser um funcionário que cumpre ordens e na fase seguinte, } \\
\text { essas regras se invertem. Se x e } \mathrm{T}_{1} \text {, faço; se x e } \mathrm{T}_{2} \text {, não faço. }\end{array}$ & $\begin{array}{l}\text { Controle } \\
\text { Inibitório } \\
\text { Flexibilidade } \\
\text { Cognitiva }\end{array}$ \\
\hline Md - Mirar e atingir & $\begin{array}{l}\text { Situações que requerem analisar e selecionar (posição alvo, ângulo de } \\
\text { lançamento) antes de executar a ação; Requerem precisão e estratégia } \\
\text { visomotora; Envolve lançamentos horizontais. Por exemplo, manejar arco- } \\
\text { flecha, catapulta, arma, estilingue, etc. Se x, quando T, então faço. }\end{array}$ & $\begin{array}{l}\text { Controle } \\
\text { Inibitório }\end{array}$ \\
\hline $\begin{array}{l}\text { Me - Gerenciar fatores } \\
\text { externos que interferem } \\
\text { no progresso ou sucesso } \\
\text { da tarefa em curso } \\
\quad \text { (objetivo) }\end{array}$ & $\begin{array}{l}\text { Situações em que a atenção no contexto geral (variável) é o fator mais } \\
\text { importante durante a execução para o sucesso da tarefa; Requer monitoramento } \\
\text { prolongado associado a reação rápida; Envolve situações de aleatoriedade e } \\
\text { randomicidade. Por exemplo, resgatar um soldado (objetivo), desviando de } \\
\text { obstáculos (trajeto) atirando e se protegendo dos inimigos que não se tem } \\
\text { previsão do local de surgimento, rota e frequência de aparição; dirigir um } \\
\text { automóvel num simulador de trânsito com presença de variáveis não } \\
\text { controláveis pelo jogador (ciclistas, pedestres, semáforos, animais, etc). É a } \\
\text { versão da Mb com objetivos maiores e que podem transpor a fase ou nível. }\end{array}$ & $\begin{array}{c}\text { Flexibilidade } \\
\text { Cognitiva }\end{array}$ \\
\hline $\begin{array}{l}\text { Mf - Planejar as ações } \\
\text { antes de executá-las, } \\
\text { buscando o melhor } \\
\text { trajeto ou solução ótima }\end{array}$ & $\begin{array}{l}\text { Dadas várias possibilidades, encontrar a que requer menor gasto ou o maior } \\
\text { ganho; Antever os passos necessários para atingir o objetivo, ordenando-os. Por } \\
\text { exemplo, se x, então y =k, t, w...n, sendo que existe y ótimo. }\end{array}$ & $\begin{array}{l}\text { Memória de } \\
\text { Trabalho } \\
\text { Flexibilidade } \\
\text { Cognitiva }\end{array}$ \\
\hline $\begin{array}{l}\text { Mg - Resolver enigmas } \\
\text { ou identificar padrões } \\
\text { lógicos }\end{array}$ & $\begin{array}{l}\text { Decifrar charadas, analisar sequências e situações buscando regras e padrões de } \\
\text { repetição. Requer construir mentalmente várias soluções ou regras que } \\
\text { justificam a recorrência de aparição; procurar similaridade ou correspondência. } \\
\text { Por exemplo, se a } i \rightarrow b i, \text { com } \mathrm{i}=1, \ldots, \mathrm{n} \text {, então existe } \mathrm{A} \rightarrow \mathrm{B} \text {. }\end{array}$ & $\begin{array}{l}\text { Memória de } \\
\text { Trabalho } \\
\text { Flexibilidade } \\
\text { Cognitiva }\end{array}$ \\
\hline $\begin{array}{l}\text { Mh - Rotacionar } \\
\text { mentalmente objetos, } \\
\text { buscando a solução } \\
\text { ótima }\end{array}$ & $\begin{array}{c}\text { Requer imaginar espacialmente as faces e ângulos de objetos ou peças que se } \\
\text { encaixam ou são complementares; Simular espacialmente diferentes pontos de } \\
\text { vista; completar espacialmente formas e figuras. Por exemplo, jogos de encaixe, } \\
\text { quebra-cabeça. }\end{array}$ & $\begin{array}{c}\text { Flexibilidade } \\
\text { Cognitiva }\end{array}$ \\
\hline
\end{tabular}




\begin{tabular}{|c|c|c|}
\hline $\begin{array}{l}\text { Mi - Recordar } \\
\text { sequência de tarefas a } \\
\text { cumprir }\end{array}$ & $\begin{array}{l}\text { Durante a execução, ter que recordar quais passos já foram executados e quais } \\
\text { precisam ser cumpridos, e em qual ordem/sequenciamento; Recordar } \\
\text { itens/objetos que precisam ser selecionados; Recordar regras, objetivos/metas, } \\
\text { missão ou condições de resolução; Requer suspender uma ação por um período } \\
\text { de tempo e acioná-la posteriormente, agindo oportunamente, sendo este tempo } \\
\text { de suspensão maior que o tempo de reação. Por exemplo, estar lutando com } \\
\text { inimigos e lembrar que determinado objeto na cena vale pontos extras; recordar } \\
\text { a ordem das missões sem o recurso de dicas; passos para elaboração de receita. }\end{array}$ & $\begin{array}{l}\text { Controle } \\
\text { Inibitório } \\
\text { Memória de } \\
\text { Trabalho }\end{array}$ \\
\hline $\begin{array}{l}\text { Mj - Imitar sequência } \\
\text { motora de um avatar }\end{array}$ & $\begin{array}{l}\text { Repetir os movimentos corporais instruídos no jogo (conjunto e/ou sequências } \\
\text { de setas ou do avatar), executar coreografia. Por exemplo, jogos de dança, nos } \\
\text { quais as personagens fazem os movimentos e o jogador precisa repetir. }\end{array}$ & $\begin{array}{l}\text { Memória de } \\
\text { Trabalho }\end{array}$ \\
\hline $\begin{array}{c}\text { Mk - Resistir a opções } \\
\text { de domínio ou } \\
\text { confortáveis para } \\
\text { executar tarefas } \\
\text { necessárias }\end{array}$ & $\begin{array}{l}\text { Resistir à tentação de repetir o que sabe (domínio) ou fazer o percebido como } \\
\text { mais fácil, mesmo não sendo o correto ou ótimo. É uma mecânica que pode não } \\
\text { ser explícita (percebida) pelo jogador. }\end{array}$ & $\begin{array}{l}\text { Controle } \\
\text { Inibitório }\end{array}$ \\
\hline $\begin{array}{l}\text { Ml - Parear informação } \\
\text { (tem-não tem) } \\
\text { observando diferenças } \\
\text { ou similaridades entre } \\
\text { cenas ou objetos }\end{array}$ & $\begin{array}{l}\text { Similar ao jogo de sete erros, requer descobrir elementos faltantes ou } \\
\text { incoerentes; Identificar elementos faltantes em comparação com cena padrão } \\
\text { (imaginária, do cotidiano). Por exemplo, observar que há talheres ausentes na } \\
\text { mesa de refeição. Se ai está contido em A, então à i está contido em A`. }\end{array}$ & $\begin{array}{l}\text { Memória de } \\
\text { Trabalho }\end{array}$ \\
\hline
\end{tabular}

\section{Graduação em níveis de dificuldade}

As FE são habilidades cognitivas de gestão da atenção, ou seja, que possibilitam evidenciar as informações que são relevantes para a tarefa em curso, mantendo em segundo plano (ou plano de fundo) as irrelevantes (Diamond, 2013). Neste raciocínio, quanto maior a quantidade de informações a ser analisada, maior a demanda de atenção e memória, o que implica em aumento na ativação das FE (Gazzaninga et al, 2006).

No ambiente de JDs, essa propriedade pode ser utilizada para gerar a percepção de fluxo e progresso no jogador (Smith et al, 2010; Cox \& Bittencourt, 2017), ou mesmo servir de métricas de desempenho e evolução em habilidades de FE, por exemplo, aumentando a quantidade ou velocidade dos objetos que precisam ser coletados ou destruídos (Oei et al, 2014; Schoene et al, 2015); incluir conflitos ou distrações que precisam ser gerenciadas ou evitadas (Mossmann et al, 2016; Vallejo et al, 2017); restringir o tempo para executar a tarefa (Smittenaar et al, 2015; Guimarães et al, 2016); retirar as dicas ou pistas cognitivas (Kretschmer et al, 2014; Gray et al, 2015) ou aumentar a quantidade de etapas que precisam ser memorizadas para atingir o objetivo (Tost et al, 2014; Baniqued et al, 2015; Dassen et al, 2018).

Por exemplo, o JD Boson X foi adaptado para reduzir a tendência ao pensamento fixo e obsessivo de pessoas em estado depressivo (ruminação), que dificultam a tomada de decisão (Kuhn et al, 2018). O JD consiste de um avatar fixo que simula uma corrida por um túnel (acelerador de partículas), cuja plataforma (piso) é composta por placas móveis, que precisam ser gerenciadas rapidamente, para impedir que o avatar caia do túnel. Os autores manipularam o jogo de modo que o tempo de escolha e decisão em qual placa pisar (deslocamento lateral) foi associado com a velocidade de mudança das placas (posição e dimensão) e a pontuação (taxa de energia), estimulando o jogador a progressivamente tomar uma decisão cada vez mais rápida.

$\mathrm{Na}$ aplicação do workshop, a ideia de level design foi apresentada teoricamente, porém não foi explorada pelos participantes. No entanto, observou-se que este atributo de JD estava inerente nas discussões sobre as mecânicas durante a aplicação do workshop e poderia facilitar a 
interpretação das mesmas, quando no estabelecimento da relação com as FE. Diante deste achado, optou-se por incluir este elemento no Modelo IcJJ.

Baseado no mesmo conjunto de artigos utilizados para extração das mecânicas de JD (Krause et al, 2018) foram identificadas 13 estratégias de level design (Quadro 5) utilizadas para graduar a dificuldade dos componentes executivos em videogames e exergames (Krause et al, 2019b). A divisão entre videogames e exergames se justificou devido à concepção de duplatarefa (cognitiva e motora) que por si, apresenta maior recrutamento de FE ao exigir a coordenação e flexibilização de ações entre estas duas categorias de processamento da informação.

Quadro 5: Level design em JD associados a FE (CI = controle inibitório, MT = memória de trabalho, FC = flexibilidade cognitiva, FG = funções executivas gerais e $(*)$ sem relação identificada)

\begin{tabular}{|l|c|c|}
\hline \multicolumn{1}{|c|}{ Elementos de level design em JD } & $\begin{array}{c}\text { FE } \\
\text { Videogames }\end{array}$ & $\begin{array}{c}\text { FE } \\
\text { Exergames }\end{array}$ \\
\hline D1: Presença/ausência de tempo para jogador & $\begin{array}{c}\text { CI, MT, FC, } \\
\text { FG }\end{array}$ & FG \\
\hline D2: Quantidade de elementos alvo & CI, MT, FC & FG \\
\hline D3: Velocidade dos elementos & CI, FC & FG \\
\hline D4: Presença/ausência de pontuação para o jogador & CI & FC, FG \\
\hline D5: Presença/ausência/quantidade de distradores ou obstáculos & MT & FG \\
\hline D6: Quantidade de movimentos necessários para atingir o objetivo & MT & FC \\
\hline D7: Quantidade de tentativas (margem de erro) & CI, FC & FG \\
\hline D8: Presença/ausência de condição ou restrição & CI, FC & FG \\
\hline D9: Presença/ausência de pista cognitiva & CI, MT, FC & FG \\
\hline D10: Presença/ausência/quantidade de vidas ou munição & CI, FC & FG \\
\hline D11: Dimensão/tamanho do objeto & FG & $*$ \\
\hline D12: Presença/ausência de elementos agressivos & CI & $*$ \\
\hline D13: Presença/ausência de feedback & FG & $*$ \\
\hline
\end{tabular}

De acordo com o estudo de Krause et al (2019b), apenas cinco artigos de 31 utilizaram um único descritor do Quadro 5 e os associaram à FE gerais, os demais aplicaram uma combinação deles num mesmo JD, dificultando a construção de uma relação contundente de DnFE por componente isolado.

Os descritores (Quadro 5) foram reorganizados por método dedutivo, mantendo a relação inicial Dn-FE, detalhados e contextualizados, sem diferenciar por tipo de JD. Este processo configurou um novo conjunto de estratégias de level design em JD utilizadas para criar a complexidade em FE, constituindo-se de oito categorias $\left(\operatorname{Ld}_{n}-\mathrm{FE}\right)$, especificados no Quadro 6. 
Quadro 6: Relação entre level design de JD e componentes de FE

\begin{tabular}{|c|c|c|c|c|c|}
\hline $\begin{array}{l}\text { Ini } \\
\text { cial }\end{array}$ & \multicolumn{3}{|c|}{ Elementos de Level Design em JD } & Descrição & $\begin{array}{l}\text { Funções } \\
\text { Executivas }\end{array}$ \\
\hline \multirow{2}{*}{ D1 } & \multirow{2}{*}{$\begin{array}{l}\text { Ld1 - } \\
\text { Tarefa ou ação } \\
\text { com tempo }\end{array}$} & \multicolumn{2}{|c|}{$\begin{array}{l}\text { ilimitado/ausente; } \\
\text { restrito (limitado/pré- } \\
\text { definido com a consequência } \\
\text { de finalizar a jogada) }\end{array}$} & $\begin{array}{l}\text { associado com o gerenciamento da tarefa: } \\
\text { aumento do foco na tarefa (concentração); } \\
\text { aumento na resposta motora (agilidade); tomada } \\
\text { de decisão rápida; aumento da tensão, } \\
\text { necessitando suprimir a ansiedade para dar fluxo } \\
\text { à informação cognitiva }\end{array}$ & $\begin{array}{l}\text { Controle } \\
\text { Inibitório } \\
\text { Memória de } \\
\text { Trabalho }\end{array}$ \\
\hline & & \multicolumn{2}{|c|}{$\begin{array}{l}\text { condicional (limitado/pré- } \\
\text { definido com sistema de } \\
\text { conversão de ganho/perda de } \\
\text { pontos/vidas) }\end{array}$} & associado ao sistema de recompensa, motivação & $\begin{array}{l}\text { Flexibilidade } \\
\text { Cognitiva } \\
\text { FE gerais }\end{array}$ \\
\hline \multirow{2}{*}{ D3 } & \multirow{2}{*}{$\begin{array}{l}\text { Ld2- } \\
\text { Velocidade de } \\
\text { aparição dos } \\
\text { objetos e ritmo } \\
\text { do jogo }\end{array}$} & \multicolumn{2}{|c|}{$\begin{array}{l}\text { fixa (estático, } \\
\text { constante) }\end{array}$} & \multirow{2}{*}{$\begin{array}{l}\text { objetos que surgem para o jogador e requerem } \\
\text { uma ação ou tomada de decisão, o tempo de } \\
\text { aparição entre um objeto e outro determina o } \\
\text { ritmo imposto para reação do jogador }\end{array}$} & $\begin{array}{l}\text { Controle } \\
\text { Inibitório }\end{array}$ \\
\hline & & \multicolumn{2}{|c|}{$\begin{array}{l}\text { variada (progressivo, } \\
\text { regressivo) }\end{array}$} & & $\begin{array}{l}\text { Cognitiva } \\
\text { FE gerais }\end{array}$ \\
\hline D11 & \multirow{3}{*}{$\begin{array}{l}\text { Ld3- } \\
\text { Características } \\
\text { do elemento } \\
\text { alvo }\end{array}$} & $\begin{array}{l}\text { Dimensão, } \\
\text { forma e } \\
\text { natureza }\end{array}$ & $\begin{array}{l}\text { fixa (no } \\
\text { jogo ou fase), } \\
\text { variada, } \\
\text { constante, } \\
\text { progressiva, } \\
\text { regressiva }\end{array}$ & \multirow{3}{*}{$\begin{array}{l}\text { por exemplo, reduzir a dimensão do objeto ou } \\
\text { camuflá-lo no cenário, dificultando a percepção } \\
\text { ou acesso; coletar diversos tipos de frutas numa } \\
\text { mesma jogada; presença de elementos agressivos } \\
\text { ou que provoquem reação de medo }\end{array}$} & \multirow{3}{*}{$\begin{array}{l}\text { Controle } \\
\text { Inibitório } \\
\text { FE gerais }\end{array}$} \\
\hline \multirow{2}{*}{ D12 } & & nitidez & $\begin{array}{l}\text { explícito, } \\
\text { implícito }\end{array}$ & & \\
\hline & & $\begin{array}{l}\text { significado } \\
\text { emocional }\end{array}$ & $\begin{array}{l}\text { positivo, } \\
\text { negativo }\end{array}$ & & \\
\hline D2 & \multirow{3}{*}{$\begin{array}{l}\text { Ld4- } \\
\text { Quantidade de } \\
\text { tarefas distintas } \\
\text { (missão), etapas } \\
\text { ou elementos } \\
\text { alvo }\end{array}$} & objeto & $\begin{array}{l}\text { constante, } \\
\text { progressivo, } \\
\text { regressivo }\end{array}$ & \multirow{3}{*}{$\begin{array}{l}\text { maior número de tarefas a gerenciar, } \\
\text { aumentando a necessidade em alternar entre elas } \\
\text { mantendo o foco e não confundido regras e } \\
\text { etapas executadas; condições e restrições que } \\
\text { induzem a necessidade de criar uma estratégia } \\
\text { ou planejamento; quantidade pré-determinada a } \\
\text { ser adquirida e a duração do intervalo em que } \\
\text { elas precisam manter-se ativas em mente, } \\
\text { aumentando a carga de trabalho (memória de } \\
\text { trabalho do tipo manutenção) }\end{array}$} & \multirow{3}{*}{ 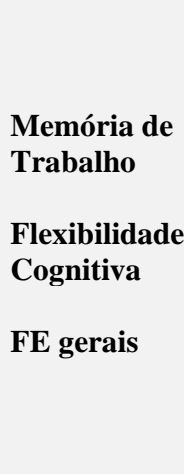 } \\
\hline \multirow[t]{2}{*}{ D6 } & & etapas & $\begin{array}{l}\text { única, } \\
\text { múltipla } \\
\text { constante, } \\
\text { progressivo, } \\
\text { regressivo } \\
\end{array}$ & & \\
\hline & & $\begin{array}{l}\text { tarefas. e } \\
\text { missões }\end{array}$ & $\begin{array}{l}\text { única, } \\
\text { múltipla, } \\
\text { simultânea, } \\
\text { alternada }\end{array}$ & & \\
\hline D8 & \multirow{4}{*}{$\begin{array}{l}\text { Lds - } \\
\text { Condições e } \\
\text { restrições } \\
\text { relacionadas } \\
\text { com a situação } \\
\text { de vitória ou } \\
\text { derrota }\end{array}$} & vidas & \multirow{4}{*}{$\begin{array}{l}\text { presente, } \\
\text { ausente, } \\
\text { condicional, } \\
\text { progressivo, } \\
\text { regressivo }\end{array}$} & \multirow{4}{*}{$\begin{array}{l}\text { situações que delineiam a margem de erro para o } \\
\text { jogador (o quanto ele pode errar sem se } \\
\text { prejudicar), induzindo a estratégia ao invés da } \\
\text { resolução por tentativa/erro }\end{array}$} & \multirow{4}{*}{$\begin{array}{l}\begin{array}{l}\text { Controle } \\
\text { Inibitório }\end{array} \\
\text { Flexibilidade } \\
\text { Cognitiva } \\
\text { FE gerais }\end{array}$} \\
\hline D7 & & tentativas & & & \\
\hline D10 & & $\begin{array}{l}\text { munição, } \\
\text { força }\end{array}$ & & & \\
\hline D4 & & pontuação & & & \\
\hline D5 & $\begin{array}{l}\text { Ld6 - } \\
\text { Elementos de } \\
\text { indução ao erro } \\
\end{array}$ & obstáculos & $\begin{array}{l}\text { presente, } \\
\text { ausente, } \\
\text { progressivo, }\end{array}$ & $\begin{array}{l}\text { por exemplo, ter de coletar moedas e encontrar } \\
\text { no cenário outros elementos que induzem a } \\
\text { confusão/erro, exigindo mais atenção; dirigir }\end{array}$ & $\begin{array}{l}\text { Memória de } \\
\text { Trabalho }\end{array}$ \\
\hline
\end{tabular}




\begin{tabular}{|c|c|c|c|c|c|}
\hline & $\begin{array}{l}\text { (distração) ou } \\
\text { obstáculos }\end{array}$ & $\begin{array}{l}\text { indução ao } \\
\text { erro }\end{array}$ & regressivo & $\begin{array}{l}\text { um veículo e ter que desviar de buracos na } \\
\text { estrada }\end{array}$ & FE gerais \\
\hline D9 & $\begin{array}{l}\text { Ld } 7- \\
\text { Pista } \\
\text { cognitiva }\end{array}$ & $\begin{array}{l}\text { presente, } \\
\text { ausente, } \\
\text { progressivo } \\
\text { regressivo }\end{array}$ & & $\begin{array}{l}\text { A presença de dicas ou pistas visuais ou } \\
\text { auditivas que reduzem a carga cognitiva, por } \\
\text { exemplo, com a recordação de regras, objetivos, } \\
\text { etapas já concluídas ou a concluir. Assim, a não } \\
\text { presença ou escassez deste elemento implica em } \\
\text { aumento da dificuldade, requerendo as funções } \\
\text { executivas. A pista cognitiva é diferente do } \\
\text { tutorial de como jogar. }\end{array}$ & $\begin{array}{l}\begin{array}{l}\text { Controle } \\
\text { Inibitório }\end{array} \\
\begin{array}{l}\text { Memória de } \\
\text { Trabalho }\end{array} \\
\begin{array}{l}\text { Flexibilidade } \\
\text { Cognitiva }\end{array} \\
\text { FE gerais }\end{array}$ \\
\hline \multirow{2}{*}{ D13 } & \multirow{2}{*}{$\begin{array}{l}\text { Ld8- } \\
\text { Feedback }\end{array}$} & frequência & $\begin{array}{l}\text { presente, } \\
\text { ausente, } \\
\text { progressivo, } \\
\text { regressivo }\end{array}$ & \multirow{2}{*}{$\begin{array}{l}\text { O retorno dado ao jogador por seu desempenho } \\
\text { (acerto/erro). A sua escassez de aparição pode } \\
\text { requer do jogador maior controle sobre seu } \\
\text { progresso e ações já executadas (situações } \\
\text { complexas), por outro lado, sua presença ativa e } \\
\text { frequente serve como um motivador, atenuando } \\
\text { a necessidade de lidar com a frustração (controle } \\
\text { emocional também exige funções executivas). }\end{array}$} & \multirow{2}{*}{ FE gerais } \\
\hline & & significado & $\begin{array}{l}\text { positivo, } \\
\text { negativo, } \\
\text { neutro }\end{array}$ & & \\
\hline
\end{tabular}

\section{$8 \quad$ O Modelo Cognitivo de Interação entre Jogo-Jogador (IcJJ)}

$\mathrm{O}$ ato de jogar é em si, uma atividade que envolve aspectos motores na coordenação dos movimentos corporais em harmonia com a percepção das imagens projetadas na tela (coordenação visomotora). No entanto, estas ações estão relacionadas e dependentes dos objetivos que o jogo impõe ao jogador ou que o próprio jogador atribui, além das restrições e possibilidades delineadas pelas regras e os demais estímulos visuais e sonoros contidos no ambiente do jogo para motivar e criar engajamento.

Esse conjunto de ações e informações precisa ser administrado pelo jogador a fim de adaptar a resposta e executar com sucesso a tarefa de jogar o jogo, o que implica no gerenciamento da atenção e do comportamento. A Figura 3 ilustra um Modelo Cognitivo para Interação entre Jogo-Jogador (IcJJ), considerando os fatores possíveis que interagem e interferem na escolha do jogador pelo jogo e durante o ato de jogá-lo:

$\checkmark$ Âmbito do jogo (à esquerda): elementos constitutivos visuais e auditivos, narrativa e personagens (temática), mecânica de regras e manipulação de objetos, níveis de dificuldade, tipo de interação com demais jogadores, dispositivos de controle e tecnologia de suporte (plataforma);

$\checkmark$ Âmbito do jogador (à direta): fatores sensoriais (visual, auditivo, cinestésico), psicomotores (amplo e fino), emocionais, culturais, cognitivos e de conhecimento prévio.

É importante ressaltar que estes processos interagem de forma dinâmica com os elementos de JD. Por exemplo, supõe-se que um jogo oferece a opção de customizar seu avatar. Para fazê-lo, através do processamento perceptivo, o jogador identifica as formas e cores do objeto, que serão confrontadas com a memória sendo atribuído um significado (processamento perceptivo) - reconhecimento do personagem. Dentre as opções ofertadas pelo jogo, o jogador irá escolher (processamento cognitivo) aquela em que mais se identifica (processamento afetivo). Para executar a ação, deverá manipular os controles e funcionalidades (processamento motor), fazendo as alterações desejadas. 


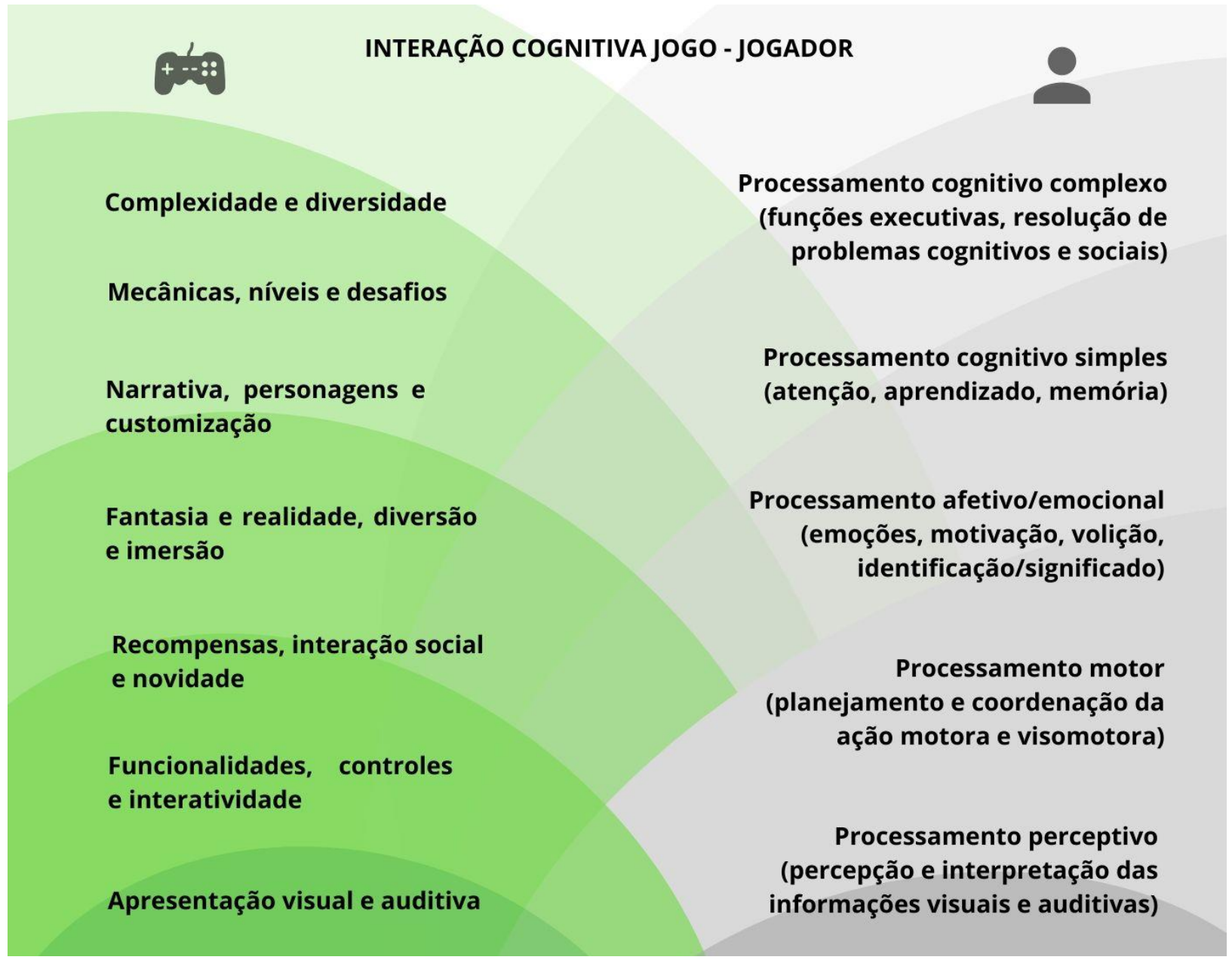

Figura 3: Modelo Cognitivo de Interação entre Jogo-Jogador (IcJJ)

Por este raciocínio, existem diversos tipos de interação entre o jogador e o jogo que podem ser investigados, por exemplo, como a personalidade do jogador interfere em seu modo de jogar e predileção de jogos (Brandão, 2016; Lazarin \& Cherobin, 2017; Moreira, 2019), qual o papel da recompensa e feedback na motivação do jogador (Li et al, 2018); elementos de JD que desenvolvem habilidades emocionais em autistas (Dantas et al, 2019) ou qual modalidade de jogo - videogame ou exergame - é mais eficaz na prevenção de quedas em idosos (Burdea $e t$ al, 2014; Kayama et al, 2014; Schoene et al, 2015; Vallejo et al, 2017).

Diante deste cenário de possibilidades, propõe-se um recorte na análise da interação do jogo com o jogador, com enfoque na modelagem dos atributos cognitivos de alto nível, especificamente as FE, requeridos pelas diferentes mecânicas de JD e graduados pelo level design. O Modelo IcJJ propõe assim que, a partir do referencial dos elementos de jogo que participam da interação com o jogador, é possível rastrear características que se sobrepõem ou se interconectam, das quais se enfatizam aquelas relacionadas com habilidades cognitivas de alto nível, como as FE dos jogadores ativadas por meio da interação com as mecânicas e o level design dos JD.

Resumidamente, o Modelo IcJJ (Figura 4) se concretiza, no presente recorte, nos quadros 4 e 6 para os elementos de jogos aqui retratados: os setores centrais discriminando os componentes das FE, os círculos representando o conjunto de 12 mecânicas e os poliedros, 
referente aos 8 elementos de level design. O modelo, entretanto, sugere que outras inter-relações possam ser desenvolvidas, mas que fogem do escopo deste trabalho.

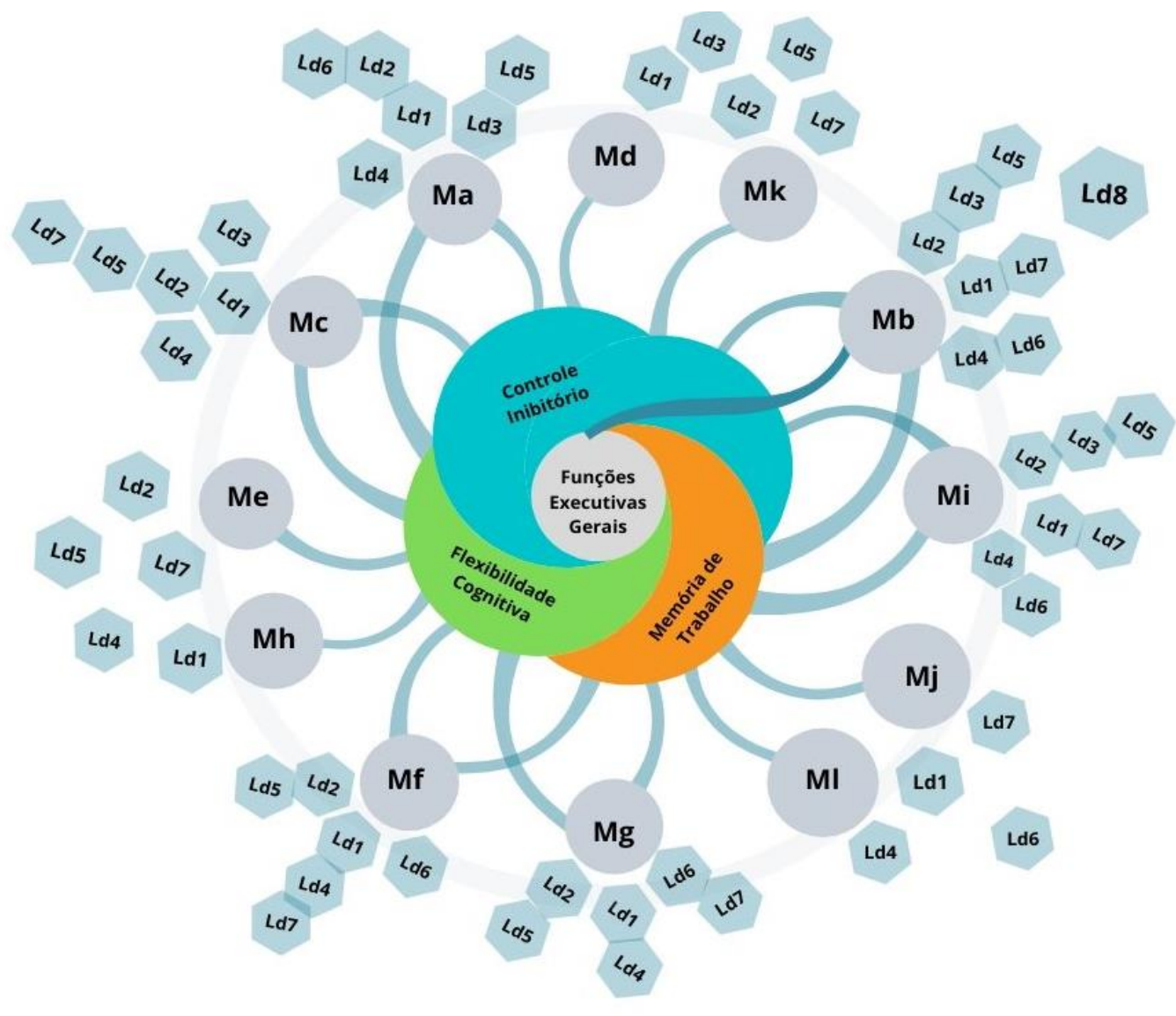

Figura 4: Modelo IcJJ relacionando FE (setores, centro), mecânicas de JD (círculos, Mn) e level design (poliedros, Ldn)

Considera-se que as FE permeiam a capacidade de aprendizado e de resolução de problemas cognitivos e sociais, por conseguinte, são fundamentais para o contexto escolar, ponto sobre o qual se argumenta que o Modelo IcJJ pode ser um ponto referencial para especialistas e não especialistas em FE na construção e/ou identificação de JD que evidenciam atributos cognitivos de alto nível, como as FE.

Ademais, a presença de JD nas salas de aula é um fato presente, no entanto, sua avaliação e escolha, pelo professor, pode ser uma tarefa complexa (Tavares, 2009), de maneira que a instrumentalização para este processo, a exemplo do Modelo IcJJ, pode tornar-se um referencial para tomada de decisão do professor.

\section{Considerações finais}

Um jogo digital (JD) é composto por diversos elementos combinados no intuito de promover a diversão e a motivação no jogador. Dentre estes elementos incluem-se as tarefas e metas a serem cumpridas, mediante regras e mecânicas que permitem sua execução. No entanto, o jogador adquire experiência conforme joga o jogo e por tal, os JD se organizam em fases e subdivisões menores, os níveis, para que a dificuldade seja gradativa e o jogador possa desenvolver habilidades no ambiente do jogo. 
Considerando que as mecânicas consistem de ações orientadas a objetivos e, juntamente com o design de níveis de dificuldade, modelam a interação do jogador com o jogo, elas requerem capacidade de resolução de problemas, controle da atenção e do comportamento; habilidades que envolvem funções cognitivas de alto nível, dentre elas, as funções executivas (FE). As FE possuem papel fundamental em comportamentos orientados para um objetivo e são compostas basicamente por três componentes de controle inibitório, memória de trabalho e flexibilidade cognitiva.

Este artigo propôs um Modelo Cognitivo de Interação entre Jogo-Jogador (IcJJ), utilizando como base a articulação dos resultados de Revisão Sistemática e de aplicação de um workshop, ambos sobre FE e JD. Como resultado, o modelo oferta uma visão sobre a interação jogo-jogador, 12 (doze) mecânicas de JD descritas, exemplificadas e relacionadas com componentes de FE, além de 8 (oito) categorias de level design (nível de dificuldade) que podem ser utilizados para graduar a complexidade em três componentes de FE nos JD.

Como limitação deste estudo, tem-se que a extração dos dados foi realizada por único pesquisador, podendo gerar viés interpretativo; a base de dados na inclui publicações em língua portuguesa e o workshop, utilizado como fonte de validação das relações estabelecidas, contou apenas com 13 participantes, não especialistas na relação entre funções executivas e jogos digitais, porém, com certo grau de conhecimento em uma das áreas, não sendo possível, desta forma, obtermos uma validação quantitativa expressa estatisticamente.

Apesar deste modelo não ser definitivo, espera-se que outros trabalhos dele sejam derivados, a citar, construção de JD sérios focados em FE podendo beneficiar um amplo espectro de condições de saúde que causam prejuízo em FE e impactam diretamente no aprendizado; seleção e avaliação de JD em relação ao seu potencial cognitivo; estudos comparativos manipulando JD a partir das relações Mn-FE propostas, refinando as evidências encontradas e ampliação da análise destas relações em JD do tipo pervasivos, locativos, colaborativos e cooperativos, que não participaram do escopo de pesquisa.

Por fim, almeja-se que o Modelo IcJJ possa auxiliar a comunicação entre os profissionais de diferentes áreas e que utilizam os JD como objeto de estudo e/ou aplicação. Além disso, auxilie a tomada de decisão de professores que vislumbram aplicar os JD como recurso de fomento ao desenvolvimento de habilidades cognitivas, a exemplo das FE que dão suporte à capacidade de autodisciplina, persistência, autoconsciência e pensamento flexível; diretamente associadas com o sucesso social, econômico e educacional.

\section{Agradecimentos}

Este trabalho foi realizado com apoio do Programa de Bolsas de Monitoria de Pós-GraduaçãoPROMOP da UDESC a qual agradecemos pelo fomento e incentivo à pesquisa. Agradecemos o apoio financeiro da FAPESC, Edital FAPESC/CNPQ N06/2016, T.O. Nº:2017TR1755 Ambientes Inteligentes Educacionais com Integração de Técnicas Learning Analytics e Gamificação e FAPESC Edital No 01/2016 - Termo de Outorga no 2017TR649 - Processo 531/2017- Apoio a Grupos de Pesquisa da Universidade do Estado de Santa Catarina (UDESC) e ao CNPq pela bolsa produtividade DT-2. 


\section{Referências}

Anderson-Hanley, C., Barcelos, N. M., Zimmerman, E. A., Gillen, R. W., Dunnam, M., Cohen, B. D. \& Maloney, M. (2018). The Aerobic and Cognitive Exercise Study (ACES) for community-dwelling older adults with or at-risk for mild cognitive impairment (MCI): neuropsychological, neurobiological and neuroimaging outcomes of a randomized clinical trial. Frontiers in Aging Neuroscience, 10 (76). doi: 10.3389/fnagi.2018.00076 [GS Search]

Arnab, S., Lim, T., Carvalho, M. B., Bellotti, F., De Freitas, S., Louchart, S., \& De Gloria, A. (2015). Mapping learning and game mechanics for serious games analysis. British Journal of Educational Technology, 46 (2), 391-411. Doi: 10.1111/bjet.12113 [GS Search]

Avila-Pesantez, D., Rivera, L. A., Vaca-Cardenas, L., Aguayo, S. \& Zuñiga, L. (2018). Towards the improvement of ADHD children through augmented reality serious games: Preliminary results. In Global Engineering Education Conference, 843-848. doi: 10.1109/EDUCON.2018.8363318 [GS Search]

Baniqued, L., Allen, M., Kranz, M. B., Johnson, K., Sipolins, A., Dickens, C. \& Kramer, A. F. (2015). Working memory, reasoning, and task switching training: transfer effects, limitations, and great expectations?. PLoS One, 10 (11). Doi: 10.1371/journal.pone.0142169 [GS Search]

Baranyi, R., Perndorfer, R., Lederer, N., Scholz, B. \& Grechenig, T. (2016). My Daily Routinea serious game to support people suffering from a cerebral dysfunction. In International Conference on Serious Games and Applications for Health, 1-6. doi: 10.1109/SeGAH.2016.7586283 [GS Search]

Bott, W. R.; Kramer, A. F.; Simons, D.; Fabiani, M. \& Gratton, G. (2008). The effects of vídeo game playing on attention, memory, and executive control. Acta Psychologic,129(3), 38798. Doi: 10.1016/j.actpsy.2008.09.005. [GS Search]

Brandão, L. R. G. (2016). Doze elementos emergenciais provenientes da mecânica e do comportamento do jogador. In: XV Simpósio Brasileiro de Jogos e Entretenimento Digital, São Paulo-SP, Brasil. [GS Search]

Burdea, G., Polistico, K., Krishnamoorthy, A., House, G., Rethage, D., Hundal, J. \& Pollack, S. (2015). Feasibility study of the BrightBrainer ${ }^{\mathrm{TM}}$ integrative cognitive rehabilitation system for elderly with dementia. Disability and Rehabilitation:Assistive Technology, 10 (5), 42132. Doi: 10.3109/17483107.2014.900575. [GS Search]

Chandler, H. M. (2009). Manual de Produção de Jogos Digitais. Bookman, Porto Alegre-RS, Brasil.

Clark, D. B.; Tanner-Smith, E. E. \& Killingdworth, S. (2016). Digital games, design, and learning: A systematic review and meta-analysis. Review of Educational Research, 86(1), 79-122. Doi: 10.3102/0034654315582065 [GS Search]

Colonna, A., Smith, A. B., Smith, S., VanDenEshof, K., Orgill, J., Gringras, P. \& Pal, D. K. (2018). The Effects of Sleep on Emotional Target Detection Performance: A Novel iPadBased Pediatric Game. Frontiers in Psychology, 9(241). Doi: 10.3389/fpsyg.2018.00241 [GS Search]

Connolly, T. M., Boyle, E. A., MacArthur, E., Hainey, T., \& Boyle, J. M. (2012). A systematic literature review of empirical evidence on computer games and serious games. Computers and Education, 59(2), 661-686. Doi: 10.1016/j.compedu.2012.03.004 [GS Search] 
Cox, K. K. \& Bittencourt, R. A. (2017). Estudo bibliográfico sobre o processo de construção de jogos digitais: a necessidade de sinergia entre o educar e o divertir. Revista Brasileira de Informática na Educação - RBIE, 25(1), 16-43. Doi: 10.5753/rbie.2017.25.01.16 [GS Search]

Csikszentmihalyi, M. (2014). Teoria do Flow, pesquisa e aplicações. ComCiência, 161. [GS Search]

Dantas, A. C.; Melo, S.; Neves, L.; Milessi, T. \& Nascimento, M. Z. do. (2019). Michelzinho: jogo sério para o ensino de habilidades emocionais em pessoas com autismo ou deficiência intelectual. In Anais do XXX Simpósio Brasileiro de Informática na Educação-SBIE, Brasília-DF, Brasil. Doi: 10.5753/cbie.sbie.2019.644 [GS Search]

Dassen, F. C., Houben, K., Van Breukelen, G. J. \& Jansen, A. (2018). Gamified working memory training in overweight individuals reduces food intake but not body weight. Appetite, 124, 89-98. Doi: 10.1016/j.appet.2017.05.009 [GS Search]

Diamond, A. (2013). Executive functions. Annual Review of Psychology, 64,135-168. Doi: 10.1146/annurev-psych-113011-143750 [GS Search]

Dovis, S., Van der Oord, S., Wiers, R. W. \& Prins, P. J. (2015). Improving executive functioning in children with ADHD: Training multiple executive functions within the context of a computer game. A randomized double-blind placebo controlled trial. PloS One, 10 (4). Doi: 10.1371/journal.pone.0121651 [GS Search]

Dormans, J. (2012). Engineering Emergence: applied theory for de game design. Universiteit van Amsterdam.

Duncan, G. J., Dowsett, C. J., Claessens, A., Magnuson, K., Huston, A. C., Klebanov, P.\& Sexton, H. (2007). School readiness and later achievement. Developmental Psychology, 43(6), 1428. Doi: 10.1037/0012-1649.43.6.1428 [GS Search]

Engelhardt, C. R., Hilgard, J., \& Bartholow, B. D. (2015). Acute exposure to difficult (but not violent) video games dysregulates cognitive control. Computers in Human Behavior, 45, 85-92 doi: 10.1016/j.chb.2014.11.089 [GS Search]

Flynn, R. M., Richert, R. A., Staiano, A. E., Wartella, E. \& Calvert, S. L. (2014). Effects of exergame play on EF in children and adolescents at a summer camp for low income youth. Journal of Educational and Developmental Psychology, 4 (1). Doi: 10.5539/jedp.v4n1p209 [GS Search]

Gamito, P., Oliveira, J., Lopes, P., Morais, D., Brito, R., Cristóvão, S. \& Rebelo, S. (2013). Executive functioning in addicts following health mobile cognitive stimulation: Evidence from alcohol and heroin patients. In Proceedings of the 7th International Conference on Pervasive Computing Technologies for Healthcare - ICST, 385-388. [GS Search]

Gazzaninga, M. S.; Ivry, R. B. \& Mangun, G. R. (2006). Neurociência Cognitiva: a biologia da mente. Artmed, Porto Alegre-RS, Brasil.

Goldstein, A., Déry, N., Pilgrim, M., Ioan, M., \& Becker, S. (2016). Stress and binge drinking: a toxic combination for the teenage brain. Neuropsychologia, 90, 251-260. Doi: 10.1016/j.neuropsychologia.2016.07.035 [GS Search]

Gray, S., Robertson, J., \& Rajendran, G. (2015). BrainQuest: an active smart phone game to enhance executive function. In Proceedings of the 14th International Conference on Interaction Design and Children - ACM, 59-68. Doi: $\underline{10.1145 / 2771839.2771846}$ [GS $\underline{\text { Search] }}$ 
Guimarães, P., Tourinho, A., Vieira, J. \& Alves, L. (2016). Uma análise das possíveis contribuições do Gamebook guardiões da floresta para estimulação das funções executivas. In Anais do XV Simpósio Brasileiro de Jogos e Entretenimento Digital. [GS Search]

Howard-Jones, P. A. (2014). Neuroscience and education: myths and messages. Nature Reviews Neuroscience, 15, 817-824. [GS Search]

Iuppa, N. \& Borst, T. (2012). End-to-end Game Development: Creating Independent Serious Games and Simulations from Start to Finish. Routledge.

Katz, N. (2008). Neurociência, Reabilitação Cognitiva e Modelos de Intervenção Em Terapia Ocupacional. Grupo Gen-Livraria Santos Editora, Brasil.

Kayama, H., Okamoto, K., Nishiguchi, S., Yamada, M., Kuroda, T. \& Aoyama, T. (2014). Effect of a Kinect-based exercise game on improving executive 73 cognitive performance in community-dwelling elderly: case control study. Journal of Medical Internet Research, 16 (2). [GS Search]

Kirsh, D. (2000). A few thoughts on cognitive overload. Intellectica, 1(30), 19-51. [GS Search]

Klein, R. M., Hassan, T., Wilson, G., Ishigami, Y. \& Mulle, J. (2017). The AttentionTrip: A game-like tool for measuring the networks of attention. Journal of Neuroscience Methods, 289, 99-109. Doi: 10.1016/j.jneumeth.2017.07.008 [GS Search]

Krause K. K. G., Gasparini, I. \& Hounsell, M. da S. (2018). Aplicações de jogos digitais nas funções executivas: um mapeamento sistemático da literatura. In: Proceedings of the XVII Brazilian Symposium on Computer Games and Digital Entertainment, 54-62, Foz do Iguaçú-PR, Brasil. [GS Search]

Krause, K. K. G., Hounsell, M. da S. \& Gasparini, I. (2019a). Construindo a relação entre funções executivas e mecânicas de jogos digitais. In Anais do XXX Simpósio Brasileiro de Informática na Educação, Brasília-DF, Brasil. Doi: 10.5753/cbie.sbie.2019.1082 [GS $\underline{\text { Search] }}$

Krause, K. K. G., Hounsell, M. da S. \& Gasparini, I. (2019b). O level design de jogos digitais para funções executivas: uma revisão da literatura. In: Proceedings of the XVIII Brazilian Symposium on Computer Games and Digital Entertainment, 235-243, Rio de Janeiro-RJ, Brasil. [GS Search]

Kretschmer, A., Altgassen, M., Rendell, P. G. \& Bölte, S. (2014). Prospective memory in adults with high-functioning autism spectrum disorders: Exploring effects of implementation intentions and retrospective memory load. Research in Developmental Disabilities, 35(11), 3108-3118. Doi: 10.1016/j.ridd.2014.07.052 [GS Search]

Kuhn, D. (2006). Do cognitive changes accompany developments in the adolescent brain?. Perspectives on Psychological Science, 1(1), 59-67. Doi: 10.1111/j.17456924.2006.t01-2-.x [GS Search]

Kühn, S., Berna, F., Lüdtke, T., Gallinat, J. \& Moritz, S. (2018). Fighting depression: action video game play may reduce rumination and increase subjective and objective cognition in depressed patients. Frontiers in Psychology, 9(129). Doi: 10.3389/fpsyg.2018.00129 [GS Search]

Lazarin, L. V. \& Cherobin, R. (2017). A relação entre o processo de tomada de decisão e level design. In Proceedings of the XVI Brazilian Symposium on Computer Games and Digital Entertainment, 1264-1267, Curitiba-PR, Brasil. [GS Search] 
Leffa L.V. \& Pinto, C. M. (2018). Aprendizagem como vício: o uso de games na sala de aula. Revista (Con) textos Linguísticos, 8(10), 358-378. [GS Search]

Li, B., Atyabi, A., Kim, M., Barney, E., Ahn, A. Y., Luo, Y. \& Mademtzi, M. (2018). Social Influences on Executive Functioning in Autism: Design of a Mobile Gaming Platform. In Conference on Human Factors in Computing Systems - CHI. Doi: $\underline{10.1145 / 3173574.3174017}$ [GS Search]

Liu, Q., Zhu, X., Ziegler, A., \& Shi, J. (2015). The effects of inhibitory control training for preschoolers on reasoning ability and neural activity. Scientific Reports, 5. [GS Search]

Martínez-Pernía, D., Núñez-Huasaf, J., Del Blanco, Á., Ruiz-Tagle, A., Velásquez, J., Gomez, M. \& Slachevsky, A. (2017). Using game authoring platforms to develop screen-based simulated functional assessments in persons with executive dysfunction following traumatic brain injury. Journal of Biomedical Informatics, 74, 71-84. Doi: 10.1016/j.jbi.2017.08.012 [GS Search]

Mattar, J. (2010). Games em Educação: como os nativos digitais aprendem. Pearson Prentice Hall, São Paulo, Brasil.

McKenna, P., Lemon, O., Corley, M., Boa, D., \& Rajendran, G. (2014). One step at a time: Multimodal interfaces and children's executive functioning. In 4th International Conference on Development and Learning and on Epigenetic Robotics - IEEE, 421-425. Doi: 10.1109/DEVLRN.2014.6983018 [GS Search]

Mondejar, T., Hervas, R., Johnson, E., Gutierrez, C. \& Latorre, J. M. (2016). Correlation between videogame mechanics and executive functions through EEG analysis. Journal of Biomedical Informatics, 63, 131-140. Doi: 10.1016/j.jbi.2016.08.006 [GS Search]

Moreira, V. (2019). O perfil do jogador e as emoções no jogo. Acta Ludica-International Journal of Game Studies, 3(1), 7-35. [GS Search]

Mossann, J. B.; Reategui, E.; Barbosa, D.; Cardoso, C.; Fonseca, R. \& Viana, M. (2016). Um exergame para estimulação de componentes das funções executivas em crianças do ensino fundamental In: XV Simpósio Brasileiro de Jogos e Entretenimento Digital, São Paulo-SP, Brasil. [GS Search]

Nouwens, S., Groen, MA, \& Verhoeven, L. (2016). How storage and executive functions contribute to children's reading comprehension. Learning and Individual Differences, 47, 96-102. Doi: 10.1016/j.lindif.2015.12.008 [GS Search]

Novak, J. (2010). Desenvolvimento de Games. Cengage Learning, São Paulo-SP, Brasil.

Oei, A. C. \& Patterson, M. D. (2014). Playing a puzzle video game with changing requirements improves executive funtions. Computers in Human Behavior, 37, 216-228. Doi: 10.1016/j.chb.2014.04.046 [GS Search]

Paas, F.; Renkl, A. \& Sweller, J. (2003). Cognitive Load Theory and Instructional Design: Recent Developments. Educational Psychologist, 38(1), 1-4. Doi: 10.1207/S15326985EP3801_1 [GS Search]

Palaus, M., Marron, E. M., Viejo-Sobera, R., \& Redolar-Ripoll, D. (2017). Neural basis of video gaming: A systematic review. Frontiers in Human Neuroscience, 11. Doi: 10.3389/fnhum.2017.00248 [GS Search]

Parong, J., Mayer, R. E., Fiorella, L., MacNamara, A., Homer, B. D. \& Plass, J. L. (2017). Learning executive function skills by playing focused video games. Contemporary Educational Psychology, 51, 141-151. Doi: 10.1016/j.cedpsych.2017.07.002 [GS Search] 
Powers, K. L., Brooks, P. J., Aldrich, N. J., Palladino, M. A., \& Alfieri, L. (2013). Effects of video-game play on information processing: a meta-analytic investigation. Psychonomic Bulletin \& Review, 20(6), 1055-1079. [GS Search]

Prena, K., Reed, A., Weaver, A. J., \& Newman, S. D. (2018). Game Mechanics Matter: Differences in Video Game Conditions Influence Memory Performance. Communication Research Reports, 35(3), 222-231. Doi:10.1080/08824096.2018.1428545 [GS Search]

Rego, P.; Moreira, P. M. \& Reis, L. P. (2010). Serious games for rehabilitation: A survey and a classification towards a taxonomy. In: 5th Iberian Conference on Information Systems and Technologies, 1-6. [GS Search]

Salen, K. \& Zimmerman, E. (2012). Regras do Jogo: Fundamentos do Design de Jogos: principais conceitos, vol. 1. Blucher, São Paulo, Brasil.

Schattin, A., Arner, R., Gennaro, F. \& De Bruin, E. D. (2016). Adaptations of prefrontal brain activity, executive functions, and gait in healthy elderly following exergame and balance training: a randomized-controlled study. Frontiers in Aging Neuroscience, 8(278). Doi: $\underline{10.3389 / \text { fnagi.2016.00278 [GS Search] }}$

Schoene, D., et al (2015). Interactive cognitive-motor step training improves cognitive risk factors of falling in older adults-a randomized controlled trial. PLoS One, 10 (12). Doi: $\underline{10.1371 / \text { journal.pone.0145161 [GS Search] }}$

Shochat, G., Maoz, S., Stark-Inbar, A., Blumenfeld, B., Rand, D., Preminger, S. \& Sacher, Y. (2017, June). Motion-based virtual reality cognitive training targeting executive functions in acquired brain injury community-dwelling individuals: A feasibility and initial efficacy pilot. In International Conference on Virtual Rehabilitation - ICVR/IEEE, 1-8. [GS Search]

Smittenaar, P., Rutledge, R. B., Zeidman, P., Adams, R. A., Brown, H., Lewis, G. \& Dolan, R. J. (2015). Proactive and reactive response inhibition across the lifespan. PLoS One, 10(10). Doi: $\underline{10.1371 / \text { journal.pone.0140383 [GS Search] }}$

Sweller, J. (2016). Working memory, long-term memory, and instructional design. Journal of Applied Research in Memory and Cognition, 5(4), 360-367. Doi: 10.1016/j.jarmac.2015.12.002 [GS Search]

Tavares, R. (2009). Fundamentos de game design para educadores e não especialistas. In: Santaella, L. \& Feitoza, M. (org). Mapa do Jogo: a diversidade cultural dos games. Cengage Learning, São Paulo-SP, Brasil.

Tost, D., Pazzi, S., von Barnekow, A., Felix, E., Puricelli, S. \& Bottiroli, S. (2014). SmartAgeing: a 3D serious game for early detection of mild cognitive impairments. In Proceedings of the 8th International Conference on Pervasive Computing Technologies for Healthcar - ICST, 294-297. Doi: 10.4108/icst.pervasivehealth.2014.255334 [GS Search]

Vallejo, V., Wyss, P., Rampa, L., Mitache, A. V., Müri, R. M., Mosimann, U. P. \& Nef, T. (2017). Evaluation of a novel Serious Game based assessment tool for patients with Alzheimer's disease. PloS One, 12(5). Doi: 10.1371/journal.pone.0175999 [GS Search]

Westera, W. et al. (2008). Serious games for higher education: a framework for reducing design complexity. Journal of Computer Assisted Learning, 24(5), 420-432. Doi: 10.1111/j.13652729.2008.00279.x [GS Search]

Yeh, C. W., Cherng, R. J., \& Chen, J. Y. (2013). The effect of visuospatial working memory training in elders: Development and application of a brain fitness software. In $1 s t$ 
International Conference on Orange Technologies, 270-273. Doi: $\underline{10.1109 / \text { ICOT.2013.6521210 [GS Search] }}$

Zelazo, P. D., Blair, C. B. \& Willoughby, M. T. (2016). Executive Function: Implications for Education. NCER 2017-2000. National Center for Education Research. [GS Search] 